
\title{
R Research Soure \\ Dynamic Evaluation of Policy Feasibility, Feedbacks and the Ambitions of COALitions
}

\section{Stephen Bi ( $\nabla$ stephen.bi@pik-potsdam.de)}

Potsdam Institute for Climate Impact Research https://orcid.org/0000-0001-9631-9793

\section{Nico Bauer}

Potsdam Institute for Climate Impact Research (PIK), Member of the Leibniz Association, Germany https://orcid.org/0000-0002-0211-4162

\section{Jessica Jewell}

Chalmers University of Technology https://orcid.org/0000-0003-2846-9081

\section{Article}

Keywords: coal phase-out, climate coalitions, political feasibility, integrated assessment modeling, empirical socio-political models, energy system feedbacks, model coupling

Posted Date: November 18th, 2021

DOI: https://doi.org/10.21203/rs.3.rs-827021/v2

License: (1) (1) This work is licensed under a Creative Commons Attribution 4.0 International License. Read Full License 
1 Dynamic Evaluation of Policy Feasibility, Feedbacks and the

2 Ambitions of COALitions

3 Stephen L BI ${ }^{1,2^{*}}$, NICO BAUeR ${ }^{1}$ AND JeSSICA JeWELL $3,4,5$

$4 \quad{ }^{1}$ Potsdam Institute for Climate Impact Research (PIK), Potsdam, Germany

$5 \quad{ }^{2}$ Technical University of Berlin, Berlin, Germany

$6 \quad{ }^{3}$ Chalmers University of Technology, Gothenburg, Sweden

$7 \quad{ }^{4}$ University of Bergen, Bergen, Norway

8 International Institute for Applied Systems Analysis, Laxenburg, Austria

$9 \quad{ }^{*}$ Corresponding author, email: stephen.bi@pik-potsdam.de

\section{Abstract}

While the Paris Agreement instituted bottom-up coordination into international climate negotiations, state-of-the-art integrated assessment models (IAMs) implement policies from the top-down, distributing burdens subjectively or normatively. Here, we introduce the first evidence-based approach for emulating real-world policymaking, Dynamic Policy Evaluation (DPE). Just as IAMs rely on empirical relationships to prospectively quantify myriad techno-economic variables and simulate investment activity, DPE endogenises national policy adoption based on observed causations between IAM variables and political decisions. We demonstrate DPE on the Powering Past Coal Alliance (PPCA) via iterative feedback loops between the IAM REMIND and a policy feasibility model, deriving probabilistic scenarios with multi-stage accession. Our scenarios estimate baseline ambition toward "consigning coal to history," the $1.5^{\circ} \mathrm{C}$-consistent entry point prioritised by COP26, exposing the potential loophole of non-electric coal demand and other carbon leakage risks. We then assess path-dependencies of PPCA expansion to Covid-19 recovery actions, illustrating DPE's utility for exploring policy interactions.

\section{Introduction}

Under the Paris Agreement, 175 nations agreed to common-but-differentiated responsibilities toward limiting global warming to $1.5-2^{\circ} \mathrm{C}$ above pre-industrial levels ${ }^{1}$. While cost-effectiveness analyses (CEA) by integrated assessment models (IAMs) derive techno-economically and geophysically feasible pathways to achieve the climate targets ${ }^{2,3}$, the political feasibility of these scenarios is under scrutiny ${ }^{4-}$ ${ }^{7}$. Socio-political barriers are well-acknowledged, typically analysed through exogenously-determined 'second-best' scenarios, such as delayed action ${ }^{8}$, regionally-differentiated ambition ${ }^{9}$, or technological skepticism ${ }^{10}$. However, these still presume global policy coordination, which appears infeasible in a bottom-up international regime without credible enforcement mechanisms ${ }^{11,12}$.

Whereas CEA explores the political ambition needed to achieve stated goals, stated policy evaluation (SPE) illustrates the consequences of maintaining current ambition levels, e.g. already-implemented national policies (NPi) or nationally-determined contributions (NDCs) to Paris. SPE scenarios are often used as reference baselines for CEA and policy evaluation analyses (PEA), which assess subsequent mitigation options for their potential contribution to specified targets (Table 1). Conspicuously, for all the endogenous techno-economic dynamics represented in IAMs ${ }^{13}$, SPE and PEA rely on exogenous assumptions to prescribe policies top-down across disparate societies. To portray realistic expectations for baseline ambition and subsequent policy options, models should instead emulate the bottom-up nature of climate politics ${ }^{14,15}$. Two methodological innovations are necessary to achieve this: (i) to objectively and dynamically quantify policy feasibility ${ }^{6}$ and diffusivity ${ }^{16}$, and (ii) to harness bidirectional feedbacks between national policy adoption and the global energy economy ${ }^{7}$. 


\begin{tabular}{|c|c|c|c|}
\hline IAM Approach & Research Question & Coal Phase-Out Insight & Feasibility Focus \\
\hline $\begin{array}{l}\text { Cost- } \\
\text { Effectiveness } \\
\text { Analysis (CEA) }\end{array}$ & $\begin{array}{l}\text { What policy actions and } \\
\text { ambition levels are required to } \\
\text { achieve cost-optimal pathways } \\
\text { toward an environmental goal } \\
\text { (e.g. Paris climate targets)? }\end{array}$ & $\begin{array}{l}\text { Coal is often phased out by } \\
2050 \text { in cost-efficient, } \\
\text { Paris-compliant, } \\
\text { benchmark scenarios }{ }^{21,22} \text {. }\end{array}$ & $\begin{array}{l}\text { Endogenous assessment of a target's } \\
\text { techno-economic feasibility given } \\
\text { assumptions on future technology and } \\
\text { socioeconomic developments that may } \\
\text { include political feasibility constraints. }\end{array}$ \\
\hline $\begin{array}{l}\text { Stated Policy } \\
\text { Evaluation } \\
\text { (SPE) }\end{array}$ & $\begin{array}{l}\text { What are the long-term } \\
\text { outcomes if revealed or stated } \\
\text { ambition essentially remains } \\
\text { static over time? }\end{array}$ & $\begin{array}{l}\text { Current PPCA members } \\
\text { abate } 2.5 \mathrm{GtCO}_{2} \text { of } \\
\text { emissions from coal-fired } \\
\text { electricity }{ }^{18} \text {. }\end{array}$ & $\begin{array}{l}\text { Assessment of current policies or } \\
\text { pledges assumed to be politically } \\
\text { feasible but also to remain static. Often } \\
\text { used as baseline reference scenarios. }\end{array}$ \\
\hline $\begin{array}{l}\text { Policy } \\
\text { Evaluation } \\
\text { Analysis (PEA) }\end{array}$ & $\begin{array}{l}\text { What could a given policy (or } \\
\text { policy suite) accomplish } \\
\text { towards a stated goal if } \\
\text { adopted globally or in a } \\
\text { predetermined coalition? }\end{array}$ & $\begin{array}{l}\text { A global coal exit by } 2050 \\
\text { can account for half the } \\
\text { emissions reductions } \\
\text { required for the } 2^{\circ} \mathrm{C} \text { Paris } \\
\text { climate target }{ }^{23} \text {. }\end{array}$ & $\begin{array}{l}\text { Assessment of long-term impacts of } \\
\text { hypothetical policy options with } \\
\text { endogenous technological feasibility } \\
\text { and exogenous prescription of political } \\
\text { feasibility (or global policy adoption). }\end{array}$ \\
\hline $\begin{array}{l}\text { Dynamic } \\
\text { Policy } \\
\text { Evaluation } \\
\text { (DPE) }\end{array}$ & $\begin{array}{l}\text { Given diverse and fluid } \\
\text { national contexts, how does } \\
\text { the implied global ambition } \\
\text { toward a bottom-up initiative } \\
\text { compare to its stated goals? } \\
\text { How do the policy's energy } \\
\text { system impacts affect the } \\
\text { coalition's future growth? }\end{array}$ & $\begin{array}{l}\text { As global systems and } \\
\text { national politics co-evolve, } \\
\text { where will coal phase-out } \\
\text { policies become politically } \\
\text { feasible, and how much } \\
\text { coal can be expected to } \\
\text { phase-out by } 2050 \text { ? }\end{array}$ & $\begin{array}{l}\text { Concurrent endogenous assessment of a } \\
\text { policy's techno-economic feasibility via } \\
\text { IAM and political feasibility via empirical } \\
\text { analysis of IAM scenario data. This inter- } \\
\text { disciplinary coupling captures reciprocal } \\
\text { feedbacks between policy adoption and } \\
\text { the energy system, improving realism of } \\
\text { future policy uptake and thus emissions. }\end{array}$ \\
\hline
\end{tabular}

Here, we introduce dynamic policy evaluation (DPE), a novel IAM approach (Table 1) which fulfills both requirements to endogenise bottom-up policy coordination. Given that IAMs derive long-term energy system investment patterns consistent with empirical data and anticipated socioeconomic trends, it follows that observed policy developments can be coherently extrapolated in parallel. Recent empirical research has begun to codify causal links between national techno-economic contexts and real-world political decisions ${ }^{17-19}$, and vice-versa ${ }^{20}$. DPE merges $^{7}$ this knowledge with SPE. To wit, SPE captures the global energy system impacts of an emerging policy initiative in the variables computed, which can be input to empirical models that then systematically define policy stringencies across model regions and periods for a subsequent scenario (Methods; Figure M2). This iterative feedback loop mimics the coevolution of energy economics and energy politics; each government's behavior can be influenced by the actions of any other nation(s) or perturbations to the system.

Table 1. Approaches to IAM scenario analysis compared. Dynamic policy evaluation merges the divide between energy-economy models (e.g. IAMs), which excel in depicting long-term techno-economic feasibility, and social science research, which excels at understanding today's technology and policy landscape. DPE endogenises feedbacks between the two analytical approaches to embed socio-political dynamics into IAM scenarios, improving conventional SPE representations of baseline policy ambition and opening new doors for research on politically feasible mitigation strategies. The present study demonstrates DPE on the coal phase-out agenda.

CEA-derived mitigation strategies and international negotiations frequently prioritize the phase-out of coal $^{21,22,24}$, owing to its low economic value, high emissions factor, readier substitutes, and longer-lived capital relative to other fossil fuels ${ }^{25-28}$. The aggregate desirability of abandoning coal is further underscored by PEA demonstrations of the health and environmental benefits ${ }^{23}$. The socio-political feasibility, meanwhile, remains underexplored ${ }^{18,29,30}$. As some nations continue to commission coalfired power plants ${ }^{19,31-33}$ (Table 2), others have formed the Powering Past Coal Alliance (PPCA), an optin initiative aspiring to eradicate "unabated coal-fired electricity" by 2030 in the OECD and EU, and by 2050 in developing and emerging economies ${ }^{34}$. 
Although the 41 current national PPCA membersi comprise just $5.1 \%$ of global coal-fired electricity, this constitutes a doubling since Jewell et al. (2019). Despite grave uncertainty, SPE and PEA can essentially only depict all-or-nothing outcomes for the coal phase-out agenda (Table 1). Using DPE, we fill this exigent research gap and address the following research questions. Under standard baseline assumptions, which countries can be reasonably expected to accede, and what constitutes a plausible range of outcomes? Can the PPCA's sector-specific policy foster Paris-consistent coal declines, or is economy-wide coverage necessary? What are the relative effects of carbon leakage and renewable technology spillovers on PPCA evolution? Finally, how path-dependent is PPCA growth and efficacy to near-term coal demand uncertainties after Covid-19 ${ }^{35}$ ?

\begin{tabular}{l|r|r|r|r|r|r}
\multicolumn{1}{c|}{ World Region } & $\begin{array}{c}\text { Operating } \\
\text { Capacity } \\
\text { (GW) }\end{array}$ & $\begin{array}{c}\text { Mean } \\
\text { Plant Age } \\
\text { (yrs) }\end{array}$ & $\begin{array}{c}\text { Mean } \\
\text { Lifespan } \\
\text { (yrs) }\end{array}$ & $\begin{array}{c}\text { Capacity } \\
\text { Pipeline } \\
\text { (GW) }\end{array}$ & $\begin{array}{c}\text { Project } \\
\text { Completion } \\
\text { Rates }\end{array}$ & $\begin{array}{c}\text { Implied } \\
\text { Emissions } \\
\text { (GtCO })\end{array}$ \\
\hline Canada, AUS, NZ & 34.4 & 33.1 & 40.2 & 5.2 & $35.5 \%$ & 1.96 \\
\hline China & 1028.4 & 11.2 & 22.2 & 285.6 & $54.8 \%$ & 78.25 \\
\hline EU-27+ UK & 141.5 & 32.8 & 42.0 & 1.8 & $43.2 \%$ & 8.26 \\
\hline Former Soviet Union & 85.8 & 42.8 & 51.2 & 5.6 & $47.4 \%$ & 4.57 \\
\hline India & 225.7 & 12.3 & 38.9 & 102.7 & $35.8 \%$ & 34.73 \\
\hline Japan & 47.2 & 22.3 & 36.9 & 9.8 & $71.0 \%$ & 5.68 \\
\hline Latin America & 17.5 & 18.1 & 31.6 & 5.2 & $40.1 \%$ & 2.19 \\
\hline MENA & 9.2 & 21.3 & 36.9 & 19.9 & $43.2 \%$ & 1.06 \\
\hline Non-EU Europe & 26.4 & 22.2 & 48.0 & 29.5 & $41.8 \%$ & 5.93 \\
\hline Other Asian States & 129.2 & 11.7 & 35.0 & 154.9 & $58.8 \%$ & 25.57 \\
\hline Sub-Saharan Africa & 44.1 & 31.2 & 48.0 & 34.9 & $39.7 \%$ & 2.21 \\
\hline USA & 248.8 & 40.5 & 48.9 & 0.0 & $1.4 \%$ & 13.89 \\
\hline World & $\mathbf{2 0 5 8 . 1}$ & $\mathbf{1 8 . 5}$ & $\mathbf{3 1 . 1}$ & $\mathbf{6 5 5 . 1}$ & $\mathbf{5 0 . 1 \%}$ & $\mathbf{1 8 4 . 3}$
\end{tabular}

Table 2. Bottom-up coal power capacity statistics aggregated to REMIND's 12 world-region level, including the operating capacity in 2020, the capacity-weighted mean age of operating plants, the historical capacity-weighted mean lifespan, currently planned capacity, and the completion rate of pipeline projects from 2014-2020. The final column calculates the implied total emissions from operating and planned coal plants if these historical values are held constant in the future (neutral Covid recovery scenario). See Table A3 for implied emissions of other recovery scenarios, and Table A2 for planned capacity and completion rates of each project phase.

We define an outcome as socio-politically feasible if there are actors who have the capacity to realise it in a given context ${ }^{36}$. Thus, a national energy and climate policy is feasible if it aligns with state imperatives and if the state has sufficient capacity to overcome vested interests ${ }^{6}$. For the coal phaseout arena, Jewell et al. (2019) defined a dynamic feasibility space ${ }^{6}$ (DFS) in terms of national likelihoods of joining the PPCA. Specifically, the study analysed a pool of 2,036 regression models, permuting eleven independent variables seeking to explain PPCA membership, and established that high percapita GDP and low reliance on coal for electricity supply (coal-power-share) have particularly strong explanatory power (Figure $2 a)^{18}$. In a first attempt to quantify future policy feasibility, we use the IAM REMIND ${ }^{13}$ to provide scenario data to the DFS via the novel COALogit model, which employs spatial downscaling routines and probabilistic thresholds, or 'socio-political tipping points's7-39, within the PPCA-DFS to iteratively define country-level, evidence-based scenarios of PPCA growth for REMIND analysis (Figure 2; see Methods). 


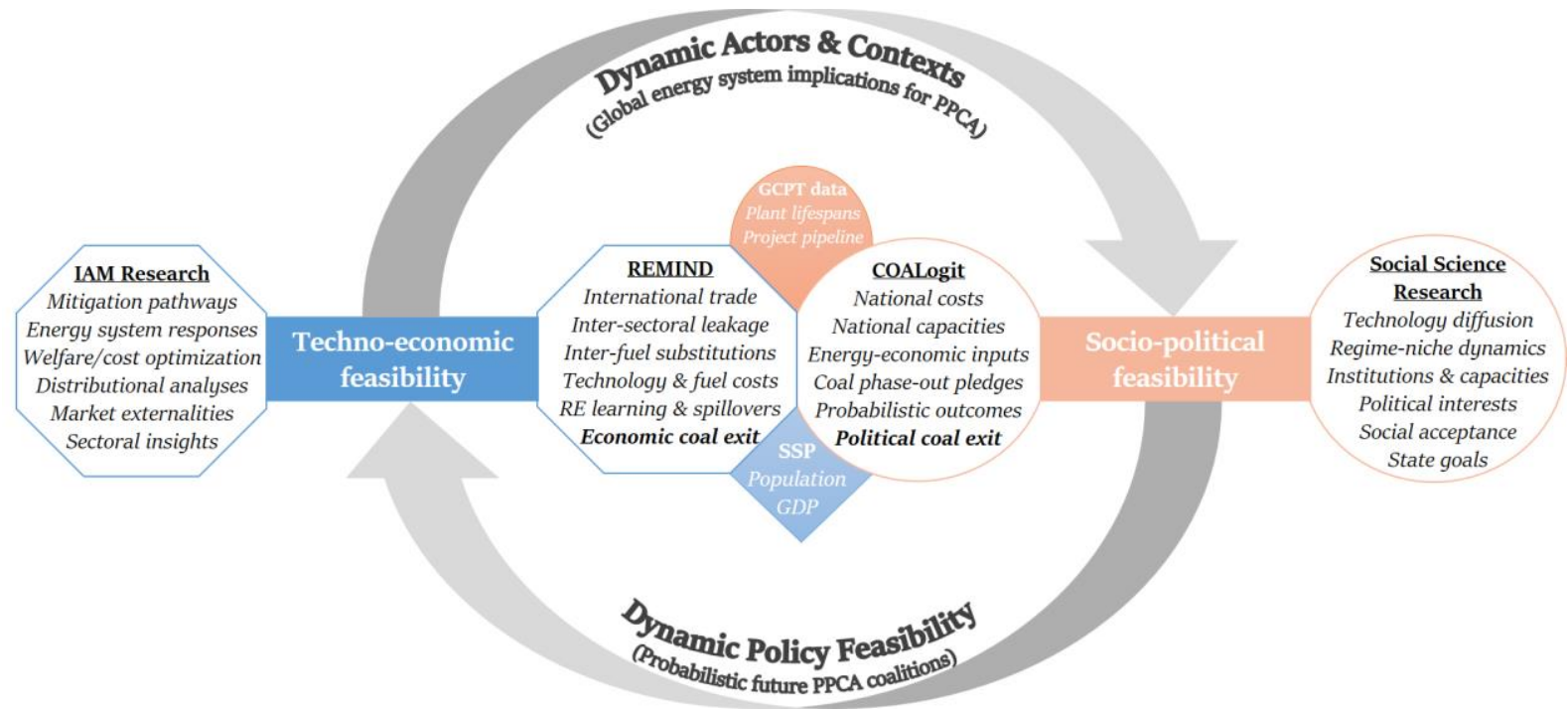

Figure 1. Dynamic Policy Evaluation depicted as a cyclical, iterative interface between techno-economic and socio-political analyses, both in the present study (inner circle and parentheses) and in the broader context of integrating IAMs and social sciences (outer circle). Policy feedbacks in this study begin with the impacts of currently legislated coal exits on national energy sectors, regional energy systems, and the global energy market, i.e. dynamic actors and contexts, via REMIND-endogenous effects (inner blue hexagon). REMIND feeds future per-capita GDP and coal-power-shares to COALogit, which infers national probabilities of PPCA accession. These political prospects are translated to coalition scenarios and policy stringency coefficients (Methods) which inform regionally-differentiated policy uptake in REMIND. Staged accession is simulated by repeating the cycle in different model time-steps.

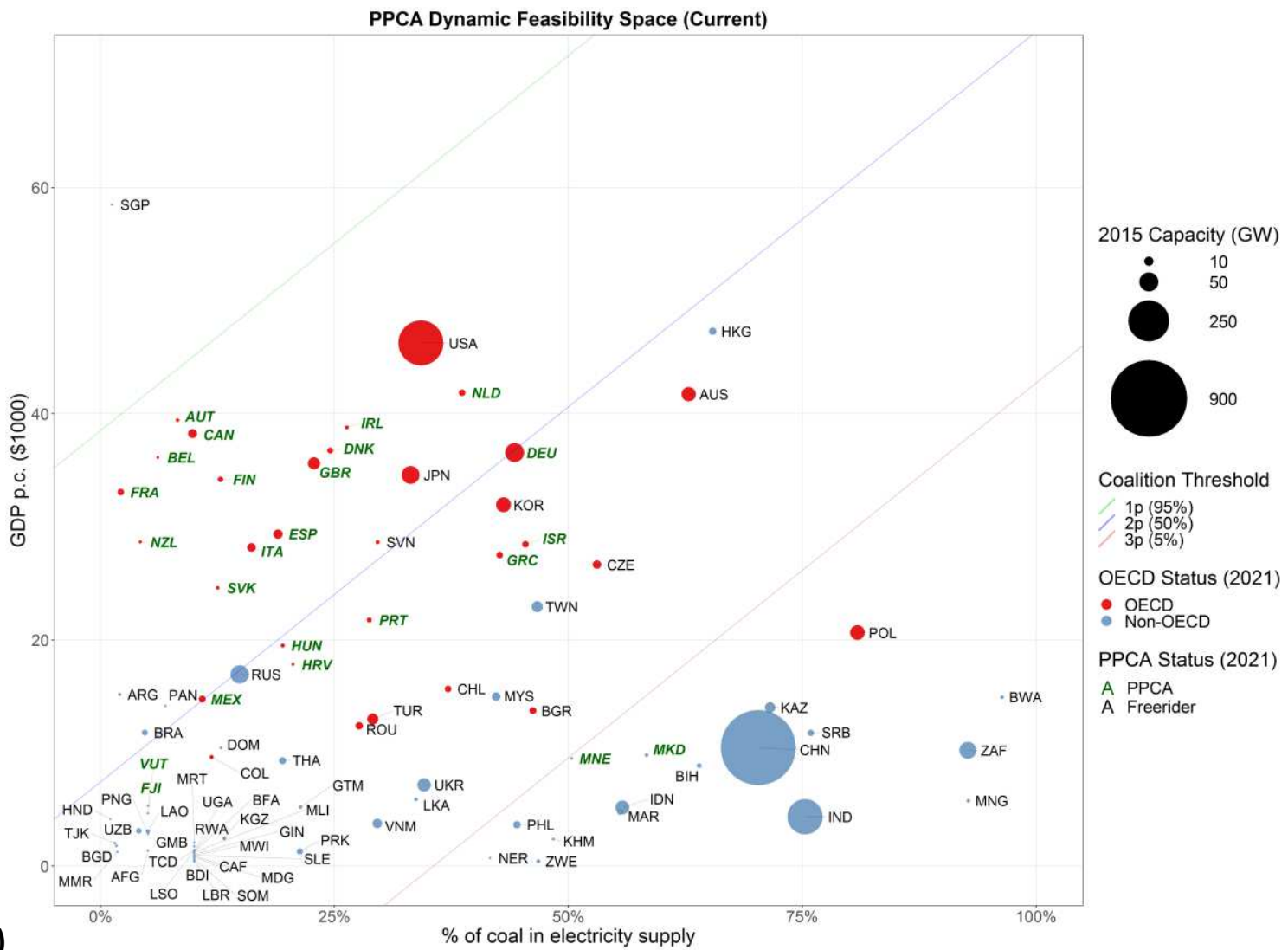


PPCA Feasibility Space (2025 Neutral Power Exit)

b)
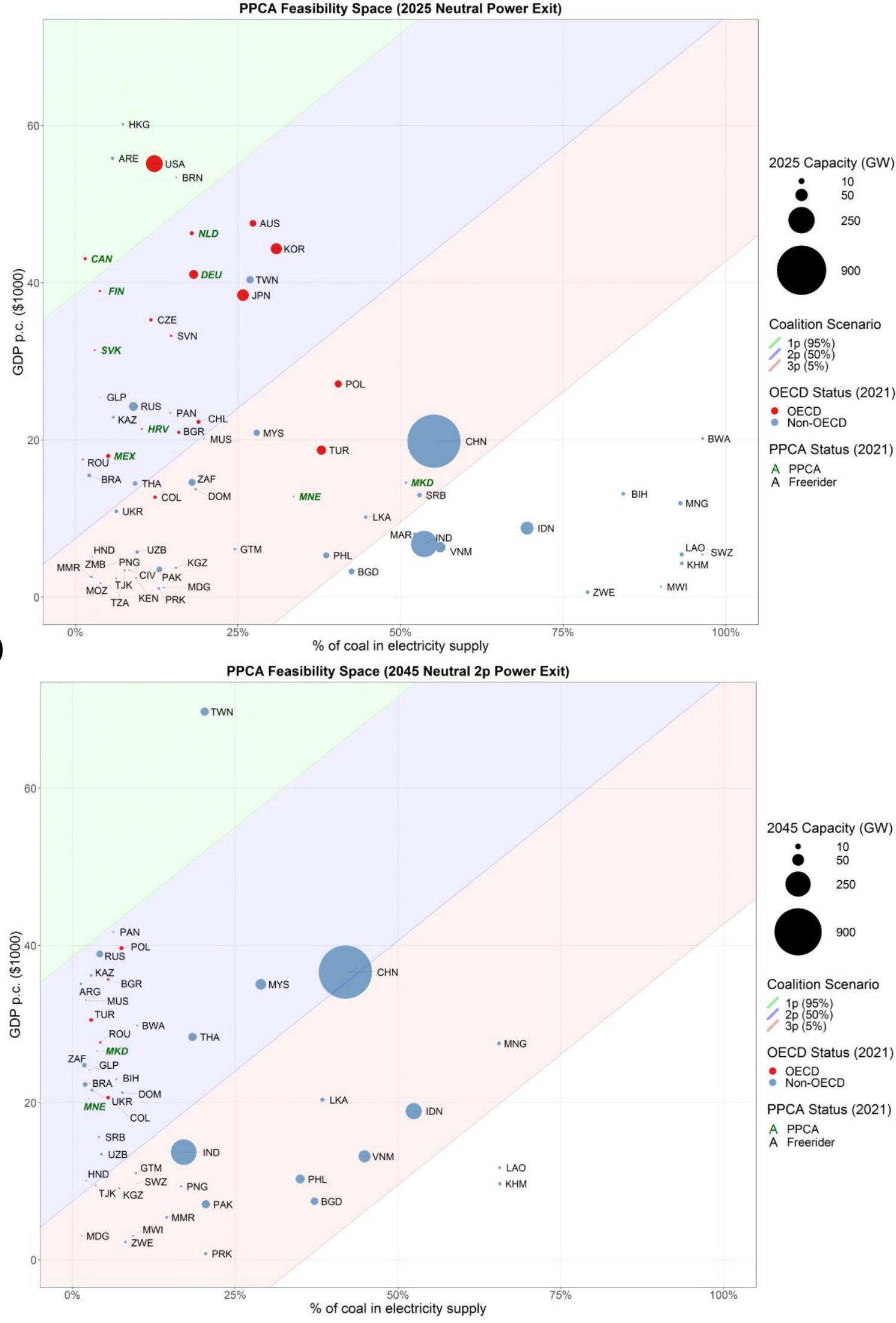


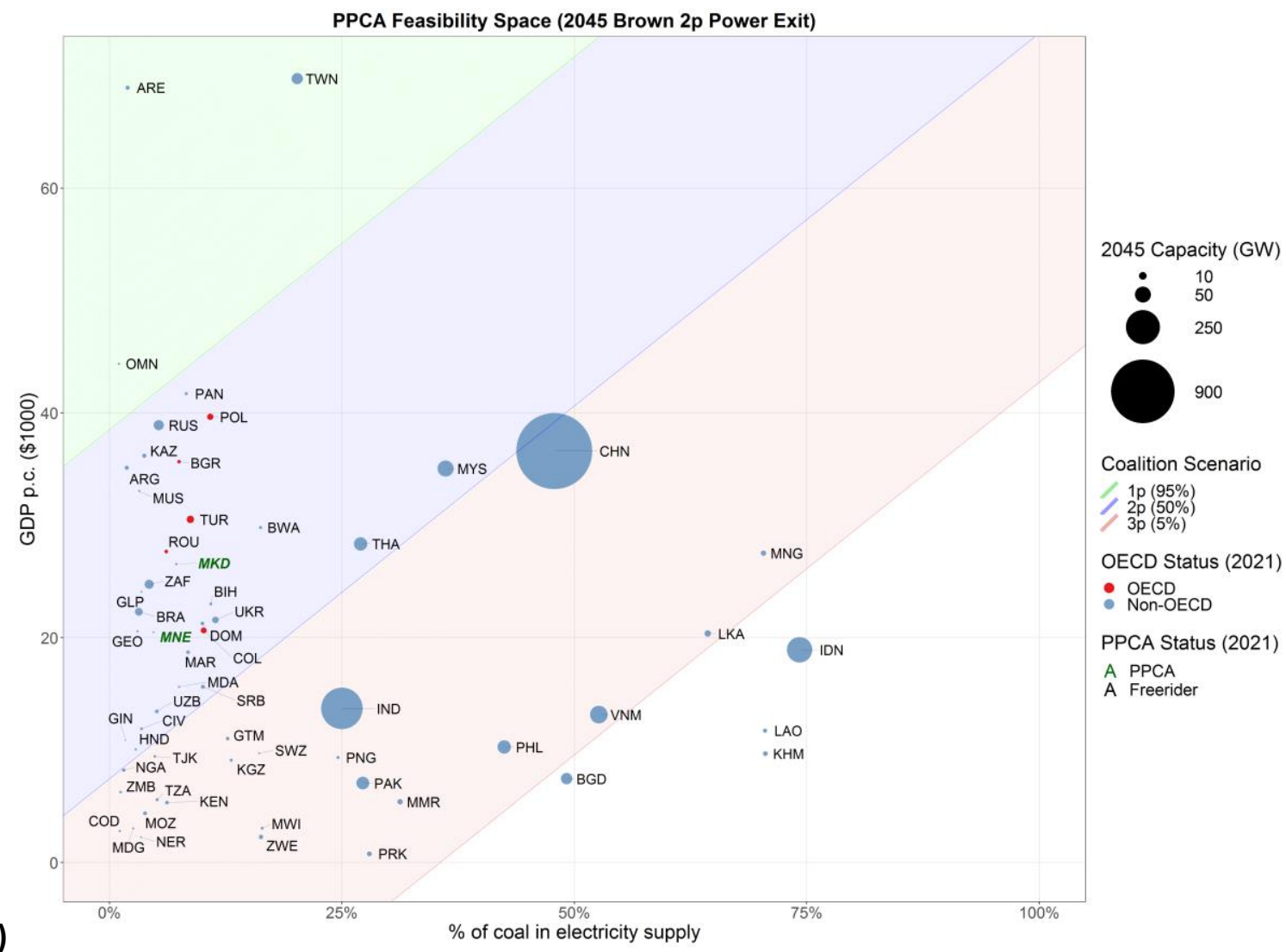

Figure 2. Dynamic feasibility of PPCA adoption in each country according to COALogit. Logistic regression of Alliance membership based on GDP per capita (indicator of state capacity) and coal-power-share (proxy for coal phase-out policy cost) in 2015 (a), 2025 (b) and 2045 (c \& d), depicting all nations with >1\% coal-power-share in the respective year. Bubble size indicates the operating coal capacity at that time, while 'PPCA Status' and 'OECD Status' reflect membership as of July 2021. The shaded areas show the probabilistic coalition scenarios: proven (1p), proven + probable ( $2 p)$, and proven + probable + possible (3p). Panels (b) and (c) represent the neutral Covid recovery - (c) follows directly from a 2030 power-exit by OECD-2p coalition members in (b) - while (d) illustrates the brown recovery, following from Figure SF1a.

\section{Results}

\section{Scenario Implementation}

To address these questions, we model 18 scenarios investigating three dimensions: coalition expansion, policy ambition, and Covid-19 recovery (Table 3). The REMIND-COALogit model-coupling framework mimics the PPCA's staged accession through an iterative cascade (Figure M4) which dynamically fragments policy stringency across model regions. We first analyse the energy system impacts of our 'median-estimate' probable-neutral scenarios alongside the analogous probable-brown scenarios, selected for the divergence in China's behavior (Figure $2 c+d$ ):

1. Power-2p-N (power-exit policy - 50\%-probable coalition - neutral recovery)

2. Power-2p-B (power-exit-50\%-probable-brown)

3. Demand-2p-N (demand-exit-50\%-probable-neutral)

4. Demand-2p-B (demand-exit-50\%-probable-brown)

Thereafter, we analyse sensitivities across each dimension using efficacy indices for coal phase-out and climate mitigation which compare scenarios on unit scales, where 0 represents reference (NPi) coal consumption or $\mathrm{CO}_{2}$ emissions and 1 corresponds to $1.5^{\circ} \mathrm{C}$ levels. 


\begin{tabular}{|c|c|c|c|c|}
\hline & $\begin{array}{l}\text { IAM } \\
\text { Mode }\end{array}$ & $\begin{array}{l}\text { Analysis } \\
\text { Dimension }\end{array}$ & $\begin{array}{l}\text { Scenario } \\
\text { Name }\end{array}$ & Scenario Definition \\
\hline \multirow{8}{*}{ 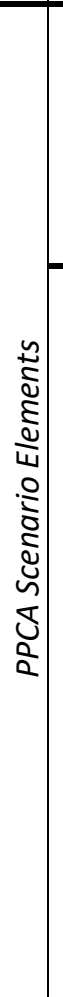 } & \multirow{3}{*}{ DPE } & \multirow{3}{*}{$\begin{array}{l}\text { Coalition } \\
\text { Expansion } \\
\text { (endogenous) }\end{array}$} & $1 p$ (proven) & $\begin{array}{l}\text { Real-world PPCA members (Table SF1) and nations assigned } \\
\geq 95 \% \text { probability of coalition accession by COALogit }\end{array}$ \\
\hline & & & $2 p$ (probable) & $1 \mathrm{p}$ plus nations above $50 \%$ coalition threshold \\
\hline & & & $3 p$ (possible) & $2 p$ plus nations above $5 \%$ coalition threshold \\
\hline & \multirow{5}{*}{ PEA } & \multirow{2}{*}{$\begin{array}{l}\text { Policy } \\
\text { Ambition } \\
\text { (exogenous) }\end{array}$} & Power-exit & $\begin{array}{l}\text { Unabated coal-fired electricity phase-out by } 2030 \text { in OECD+EU } \\
\text { coalition members and } 2050 \text { in non-OECD+EU coalition } \\
\text { members (verbatim PPCA declaration) }\end{array}$ \\
\hline & & & Demand-exit & $\begin{array}{l}\text { Unabated coal consumption phase-out along same timeline, } \\
\text { except metallurgical coal is permitted a ten-year delay ( } 2040 \\
\text { and } 2060 \text { deadlines) to reflect steel decarbonisation inertia } \\
\text { and China's } 2060 \text { carbon neutrality pledge }{ }^{40} \text {. }\end{array}$ \\
\hline & & \multirow{3}{*}{$\begin{array}{l}\text { Covid-19 } \\
\text { Recovery } \\
\text { (exogenous) }\end{array}$} & Neutral (N) & $\begin{array}{l}\text { Covid-19 recovery plans re-confirm national historical } \\
\text { tendencies in terms of project completion rates and mean } \\
\text { plant lifespans in the coal power sector until } 2025 .\end{array}$ \\
\hline & & & Green (G) & $\begin{array}{l}\text { Completion rates fall } 50 \% \text { and all shelved pre-construction } \\
\text { projects cancelled, but plant lifespans unaffected. }\end{array}$ \\
\hline & & & Brown (B) & $\begin{array}{l}\text { Project cancellation rates decline } 50 \% \text {, and plants operate } 5 \\
\text { years longer than historical national average. }\end{array}$ \\
\hline \multirow{5}{*}{ 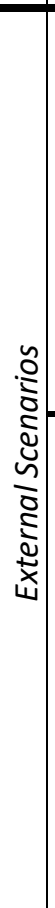 } & \multirow{2}{*}{ SPE } & $\begin{array}{l}\text { Reference } \\
\text { Scenario }\end{array}$ & NPi(-covid) & $\begin{array}{l}\text { Currently-implemented national policies, a revealed-ambition } \\
\text { scenario serving as our baseline. We model four variations: } \\
N P i-N, N P i-B \text {, and NPi-G, which correspond to each Covid } \\
\text { recovery scenario, and NPi-default, without Covid constraints. }\end{array}$ \\
\hline & & \multirow{4}{*}{$\begin{array}{l}\text { Benchmark } \\
\text { Scenarios }\end{array}$} & $N D C($-covid) & $\begin{array}{l}\text { Stated-ambition scenario assuming full compliance with the } \\
\text { first-round 'nationally-determined contributions' to the Paris } \\
\text { Agreement. We model three Covid-dependent variations } \\
(N D C-N, N D C-B, N D C-G) \text {. }\end{array}$ \\
\hline & \multirow{3}{*}{ CEA } & & $W B-2 C$ & $\begin{array}{l}\text { 'Well-below } 2^{\circ} \mathrm{C}^{\prime} \text {, a scenario with }>67 \% \text { likelihood of limiting } \\
\text { global mean temperature rise to }<2^{\circ} \mathrm{C} \text { above pre-industrial } \\
\text { levels throughout the century. Without Covid constraints. }\end{array}$ \\
\hline & & & $\mathrm{Hi}-1.5 \mathrm{C}$ & $\begin{array}{l}\text { 'Higher } 1.5^{\circ} \mathrm{C} \text { ', a scenario with }>50 \% \text { chance of achieving the } \\
1.5^{\circ} \mathrm{C} \text { target in } 2100 \text { with a moderate allowance of temporary } \\
\text { mid-century temperature overshoot. No Covid constraints. }\end{array}$ \\
\hline & & & $1.5 C$ & $\begin{array}{l}\text { Scenario with }>67 \% \text { probability of achieving } 1.5^{\circ} \mathrm{C} \text { and a } 50 \% \\
\text { chance of temporary overshoot by }<0.1^{\circ} \mathrm{C} \text {. Along with NPi- } \\
\text { default, used to define efficacy indices (Figure 4). No Covid } \\
\text { constraints. }\end{array}$ \\
\hline
\end{tabular}

Table 3. Definition of each scenario within each dimension of analysis, including reference and benchmarks. The 18 total DPE-PPCA scenarios cover every unique combination of the three 'PPCA scenario elements'. The $2 p$ coalition and neutral recovery represent our default set of assumptions, while the other scenarios are included for sensitivity analysis. We consider the two policy options (or a mixture thereof) to be similarly probable, so 
149 Following a neutral Covid-19 recovery, operating coal power capacity in 2025 declines $10 \%$ from 2020 to $1850 \mathrm{GW}$ globally (Appendix I), corresponding to a $0.8 \mathrm{EJ} / \mathrm{yr}$ reduction in coal-fired power generation. The resulting trends in national coal-power-shares and the general upward movement of per-capita GDP along the 'Middle-of-the-Road' SSP2 ${ }^{41}$ development trajectory lead 45 of 48 OECD+EU nationsii to exceed a 50\% accession probability by 2025 (Figure $2 \mathrm{~b}$ ). COALogit assigns these nations to the $2 p-N$ coalition, and the power-2p-N REMIND scenario applies the power-exit policy to them in 2030.

Using results from these intermediate REMIND scenarios (Table M2), COALogit assesses the propensity of non-OECD+EU countries to adopt a 2050 power-exit based on their per-capita GDP and coal-powershares in 2045. We find that 137 of 201 non-OECD nations cross the $2 p$-neutral threshold, so the full power- $2 p-N$ coalition comprises 182 members representing $82 \%$ of 2020 coal power generation, of which $70 \%$ was in non-OECD members.

\section{$2 p-B$ Accession}

The brown recovery, meanwhile, increases coal-fired capacity by $13 \%$ (to $2320 \mathrm{GW}$ ) and generation by $0.8 \mathrm{EJ} / \mathrm{yr}$ globally from 2020-2025. Coal-power-shares thus deviate from the neutral recovery, but percapita GDP develops identically. This leads Chile and China to abstain from accession (Figure 2d), so the power- $2 p-B$ scenario consists of 44 OECD and 136 non-OECD members, representing $36 \%$ of 2020 coal-fired electricity, $70 \%$ of which was generated by OECD nations.

Coal Market Response

The power- $2 p-N$ coalition reduces their cumulative 2020-2100 unabated coal-fired electricity by $38 \%$ compared to NPi-neutral (NPi-N) (Figure 3a). Depression of global coal market price reaches $8 \%$ by 2050 , leading to a $54 \%$ global coal leakage rate - i.e. each joule of coal phased-out incentivises $0.54 \mathrm{~J}$ of coal use in another sector or country. Meanwhile, power- $2 p-B$ coalition members reduce their reference coal electricity $24 \%$ - viz. China's abstention decreases the magnitude of the first-order effect by $80 \%$ - while coal leakage rises to $63 \%$ globally. Extra-coalition coal power demand counterintuitively declines in both scenarios, complemented by increased coal-to-liquids (CtL) and solids consumption. In either case, coalition members contribute $80 \%$ of the global coal leakage, vastly exceeding the conventional free-rider problem.

\section{Energy System Response}

Figure $3 b$ illustrates the overall primary energy (PE) demand impacts of these power- $2 p$ scenarios. Oil and gas (O\&G) account for two-thirds of the fuel switching during the OECD stage (2020-2035; see Figure M4) of power-2p-N. After the non-OECD phase-out commences in 2035, VRE dominates $93 \%$ of the energy system response. The latter phenomenon is not evident in the power- $2 p-B$ coalition, illustrating China's importance for VRE penetration and learning-by-doing spillovers. The benefits remain within the coalition, however, as VRE diffusion into free-riders increases minimally $(<0.5 \%)$ in either scenario. A global scale-back of end-use electrification across all sectors (Figure SF3b), dually disincentivised by higher power system capital costs and cheaper coal-based solids and liquids, is an apparent limiting factor of additional VRE deployment. Globally, we calculate carbon leakage rates of $54 \%$ in power- $2 p-N$ and $76 \%$ in power- $2 p-B$, over $85 \%$ of which occurs intra-coalition in both cases. 
a)

PE Coal Demand Shifts - Power Exit 2p

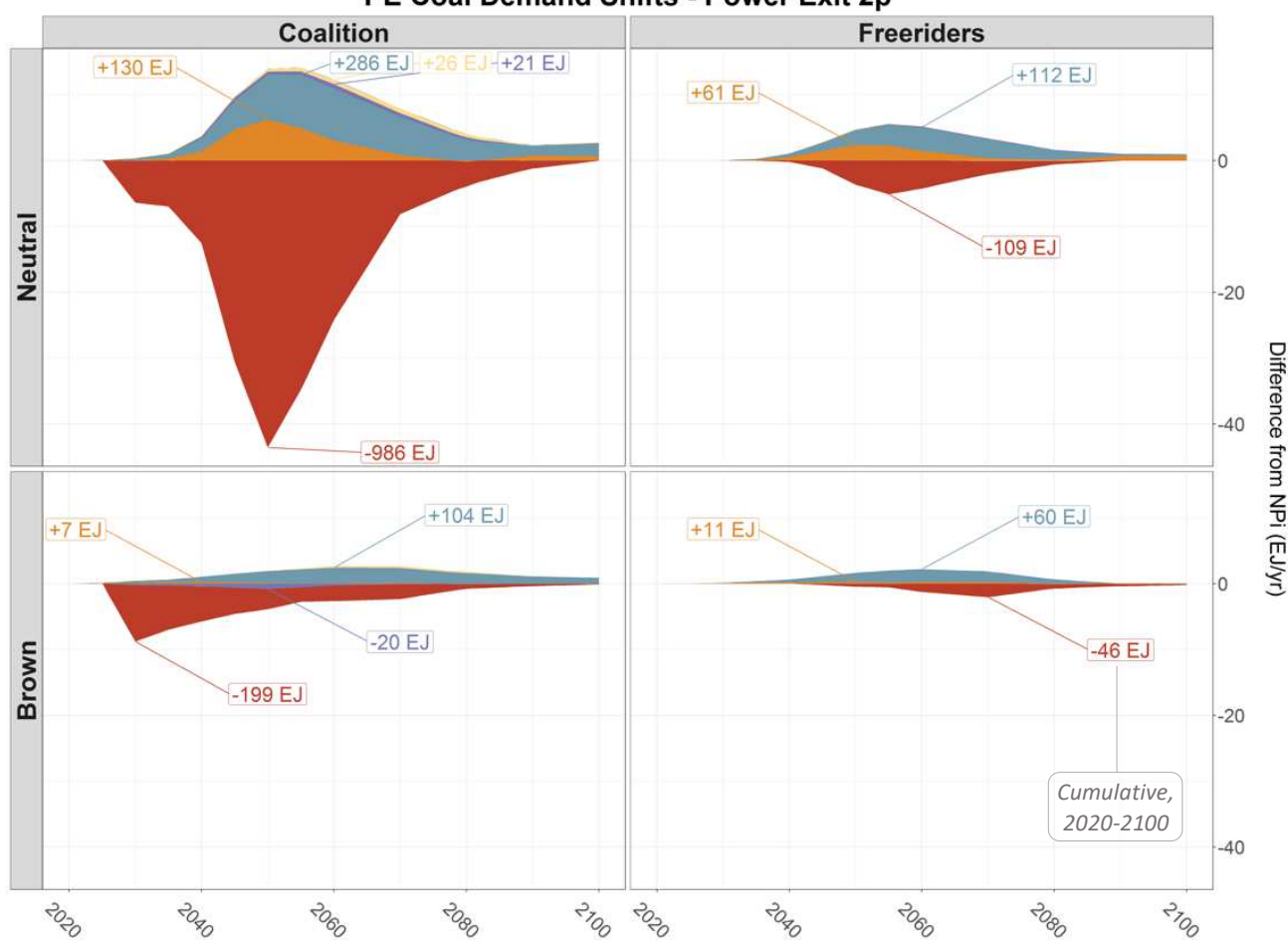

SE Conversion Route Electricity w/o CCS Electricity w/ CCS $\begin{aligned} & \text { Hydrogen } \\ & \text { Gases }\end{aligned}$

b)

Inter-Fuel PE Substitution - Power Exit 2p

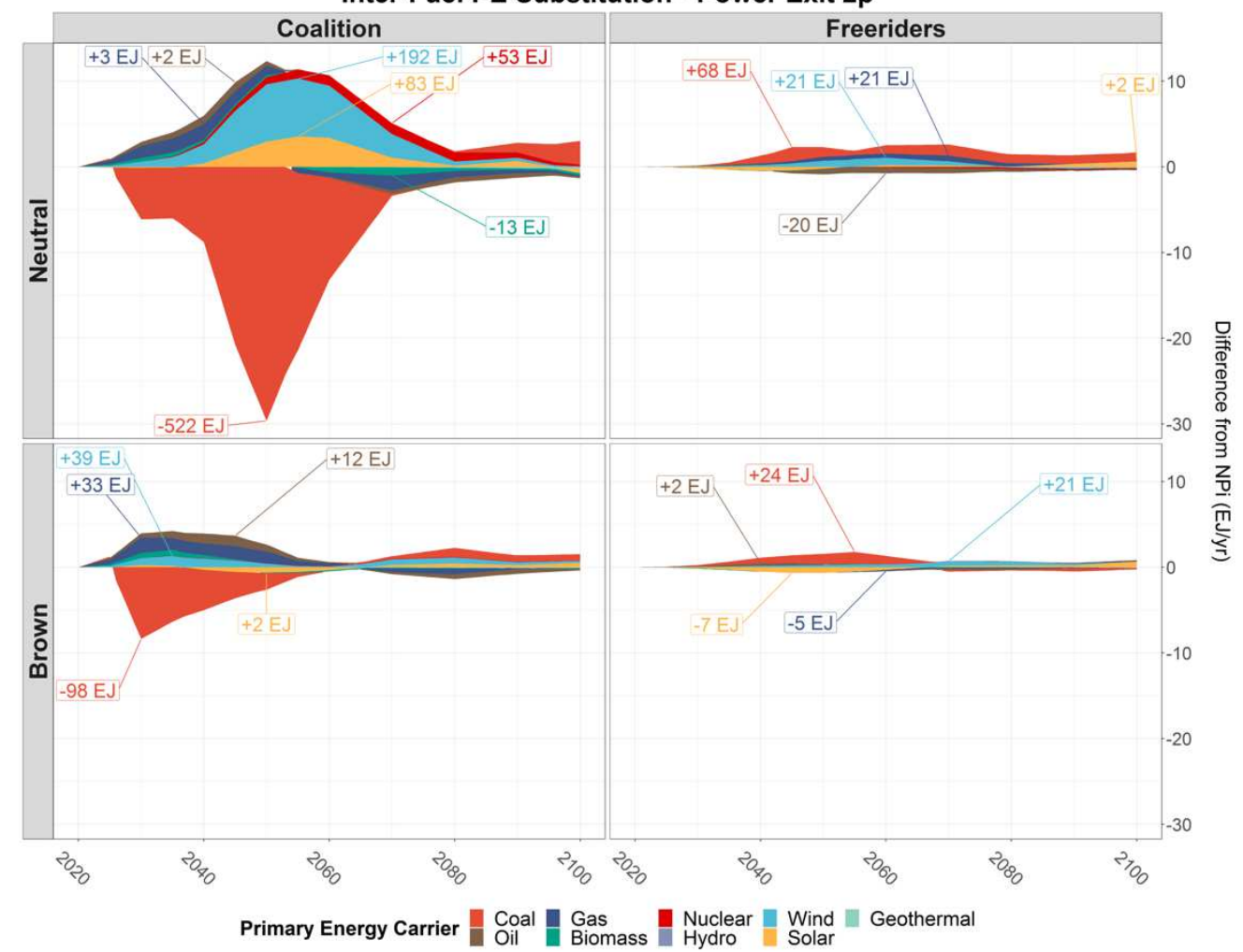


c)

PE Coal Demand Shifts - Demand Exit 2p

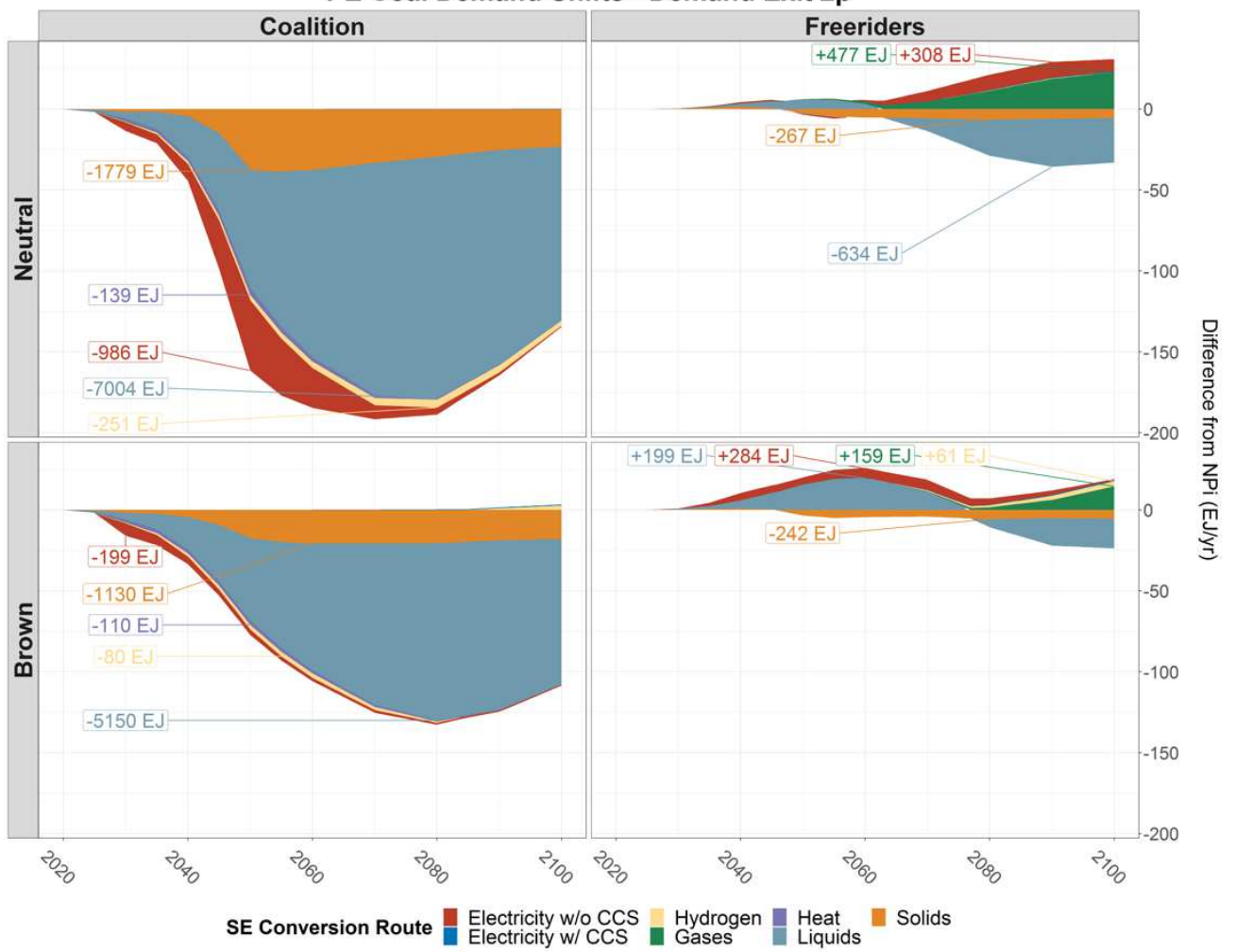

d)

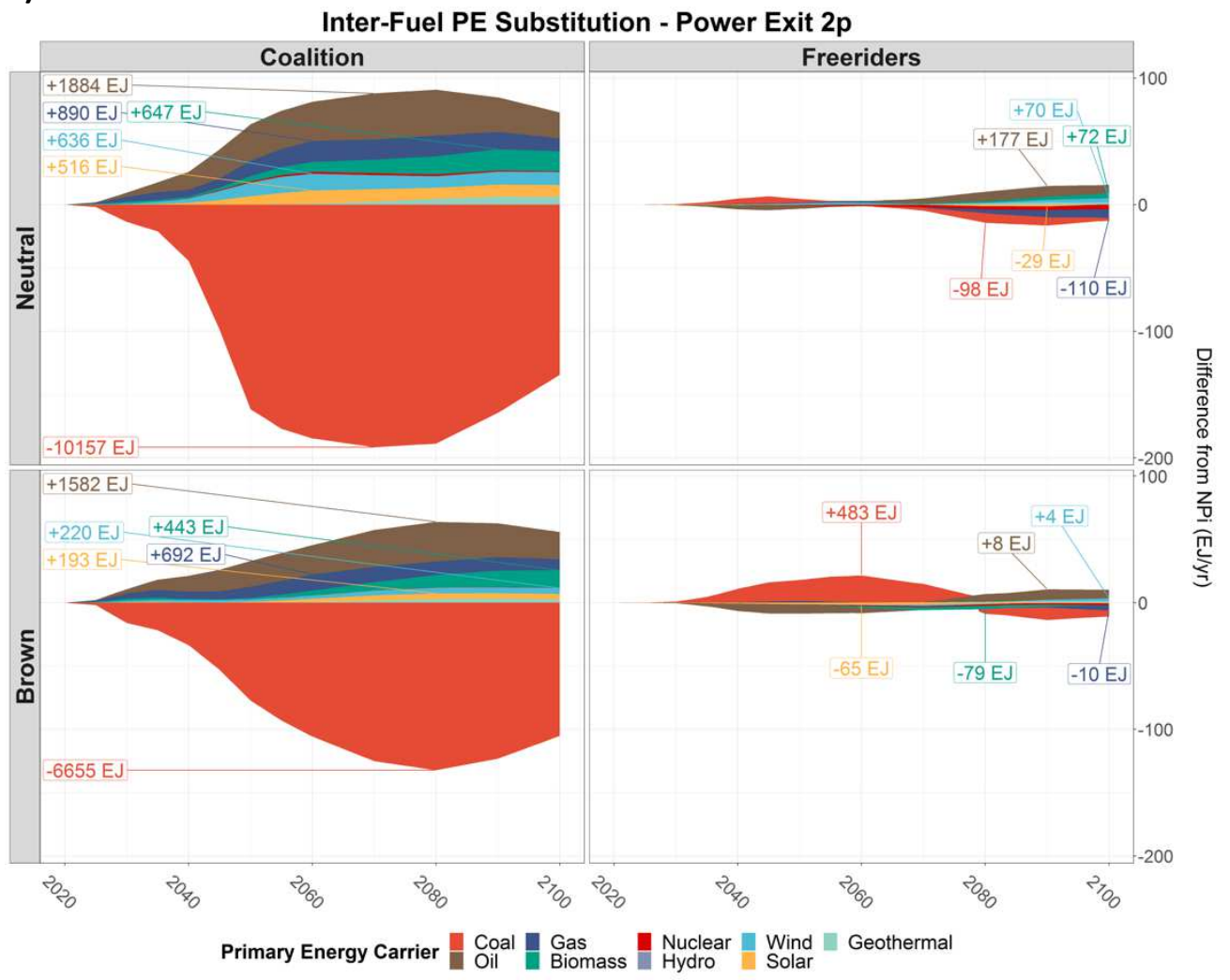

Figure 3. Annual differences in coal $(a+c)$ or primary energy $(b+d)$ demand from NPi in probable power-exit $(a-b)$ and demand-exit (c-d) scenarios, with the cumulative differences denoted by labels. Columns distinguish between coalition members and free-riders in the Covid recovery scenario represented by each row. Coal demand is given in primary energy (PE) values and categorised by secondary energy (SE) conversion route. Generally, negative areas in the 'Coalition' column reflect the intended policy effect, while all other differences indicate system feedbacks. 


\section{Power-exit Policy Evaluation}

At the global level, the power- $2 p-N$ policy-coalition scenario reduces coal use by $450 \mathrm{EJ}$ compared to NPi-N. Indexed to NPi-default, this achieves just $1.2 \%$ of the cost-efficient coal phase-out derived in the $1.5^{\circ} \mathrm{C}$ scenario. Thus, the median-estimate power-exit scores just .01 on the coal-exit efficacy index (Figure 4). The climate mitigation efficacy is even lower, scoring .01 (saving $6 \mathrm{GtCO}_{2}$ ). Still, these are considerably better outcomes than power-2p-B, which underperform NPi-default on both indices (-.02 and -.01 , respectively), implying that a global brown recovery from the Covid-19 recession may outweigh the PPCA's long-term coal and emissions reduction prospects. In any event, the verbatim power-exit contributes negligibly toward Paris-consistent abatement, assuming weak strengthening of global carbon pricing and non-electric sector regulations.

\section{Demand-Exit}

\section{Coalition Expansion}

For the demand-exit, COALogit returns a $2 p$-neutral coalition scenario identical to power- $2 p-N$. These 182 members comprise $81 \%$ of global coal demand in 2020, $25 \%$ of which was from OECD frontrunners. The demand-2p-brown coalition contains just one fewer member than power- $2 p-B$ (Serbia), totaling 179 nations which comprise $32 \%$ of 2020 coal demand. OECD members represent a $60 \%$ share.

\section{Alliance Members}

From 2020-2100, both demand-2p-N and demand-2p-B coalition members phase-out over threequarters of their respective NPi coal consumption. CtL accounts for $68 \%$ of this decline in $2 p$-neutral (77\% in $2 p$-brown) and solids for $18 \%(17 \%)$, while unabated electricity only constitutes $10 \%(3 \%)$ (Figure 3c). Intra-coalition oil demand surges $25 \%$ in both scenarios due to an oil-for-CtL swap in transport (Figure 3d), and gas demand increases $9 \%(8 \%)$, as industry's coal transition is divided between gasification and electrification (Figure SF4e). Cumulative VRE deployment increases $12 \%$ in $2 p-N$ members but just $4 \%$ in $2 p-B, 99 \%$ (96\%) of which occurs post- 2035 as the OECD again substitutes their phased-out coal primarily with O\&G ( 75\%). Biomass deployment rises $\sim 15 \%$ in either scenario, suggesting China is particularly important for VRE penetration.

\section{Free-riders}

The response of free-riding nations in demand $-2 p-N$ and demand $-2 p-B$ follow similar temporal profiles, albeit with high variance in magnitudes (Figure $3 c+d$ ). Free-riders also increase industry electrification and gasification (Figure SF4e), but fuel it with coal (Figure 3c). A knock-on coal-for-oil swap in extracoalition transport liquids is evident following the OECD phase-out - much stronger when China freerides in the brown recovery - but inverts after non-OECD adoption. Coal drives the entirety of extra-coalition carbon leakage in demand- $2 p-B$ ( $7 \%$ rate), which is just $24 \%$ of global carbon leakage ( $30 \%$ rate). In demand- $2 p-N$, free-rider leakage rates are slightly net-negative (-1\% coal, $-0.4 \%$ carbon), so intra-coalition emissions are the sole driver of the $18 \%$ global carbon leakage rate.

\section{Demand-exit Policy Evaluation}

Globally, the demand-2p- $N$ scenario results in a coal phase-out of 10,300EJ from 2020-2100 compared to $\mathrm{NPi}-\mathrm{N}$. Isolated from other policies, this $50 \%$-probable Alliance leads to a cumulative $3040 \mathrm{G}^{\mathrm{t} \mathrm{CO}_{2}}$ globally, saving 790Gt compared to NPi-N. Hence, moderate growth of a demand-exit coalition leads to efficacy indices of .52 for coal phase-out and .22 for mitigation. China's abstention is highly detrimental, as demand-2p-B scores .29 and .12 , respectively. In both cases, the adverse effect of O\&G leakage is evidenced by the $\sim 250 \%$ spread between coal and emissions abatement efficacies. 


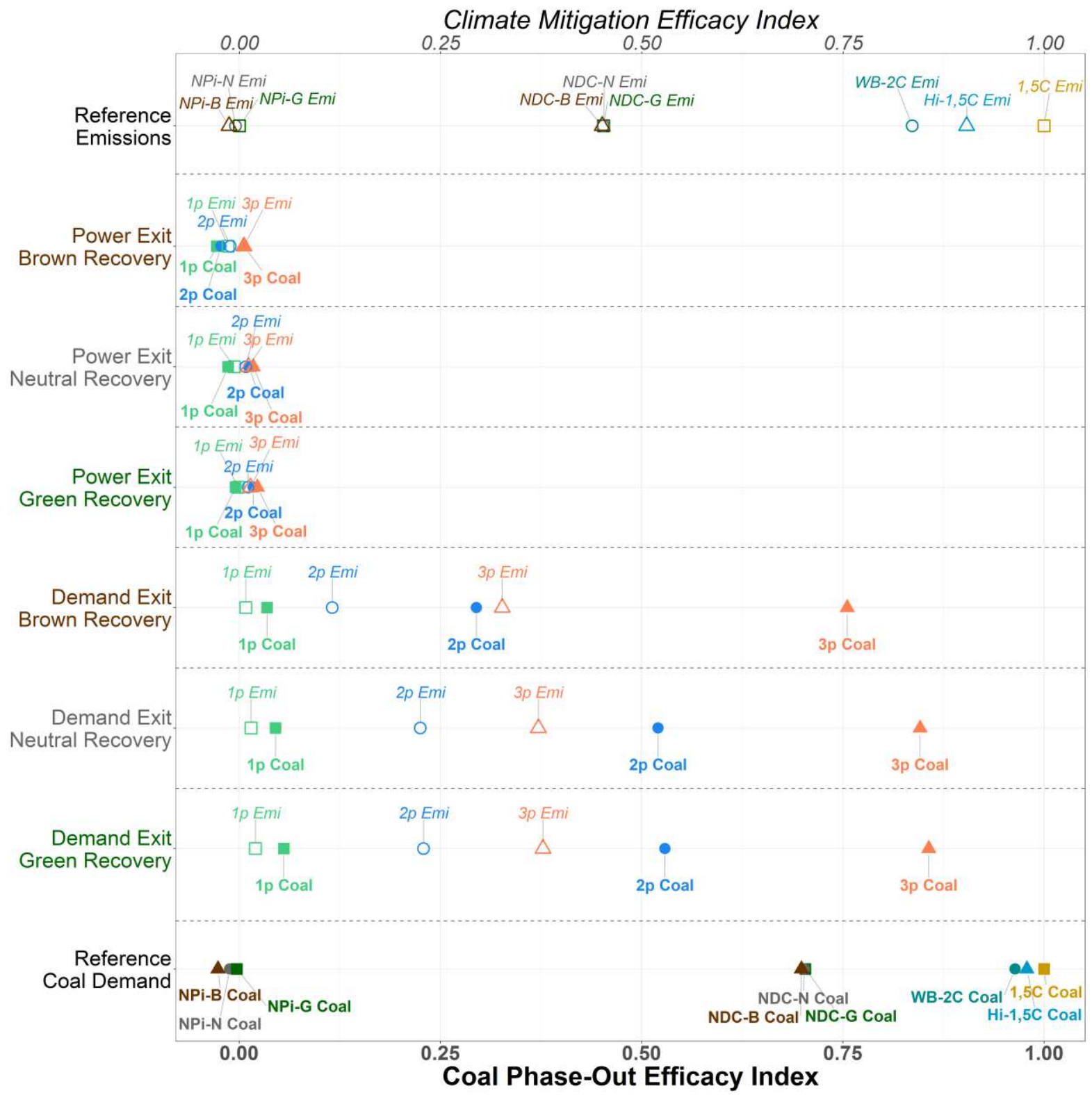

Figure 4. Compilation of all 18 scenarios, assessed for their efficacy relative to $1.5^{\circ} \mathrm{C}$ pathways in terms of coal phase-out (indicated by the lower $\mathrm{x}$-axis, solid points, and bold font) and $\mathrm{CO}_{2}$ emissions reductions (upper $\mathrm{x}$-axis, hollow points, italic font). Each scenario is scored on an index between 0 and 1 , where 0 represents the NPi reference scenario (without Covid considerations) and 1 corresponds to $1.5^{\circ} \mathrm{C}$. For each row, the $2 p$ points can be considered the DPE median estimate, and the range between $1 p$ and $3 p$ indicates the uncertainty range.

\section{Sensitivity Analyses}

\section{Coalition Growth}

\section{Efficacy Indices}

The $95 \%$-probable $1 p$ and $5 \%$-probable $3 p$ coalition scenarios embody the considerable uncertainty inherent to estimating future political decisions. For the demand-neutral case, the $1 p-3 p$ range of coal phase-out efficacy is .05-.85, and .02-.37 for emissions mitigation (Figure 4). Power-neutral scenarios have an uncertainty range of $-.01-.02$ for coal and -.01-.01 for emissions. Therefore, while the demand-exit is highly sensitive to coalition size, the power-exit is robustly inconsequential. substitutions in demand-exit simulations. We find power-1p scenarios to be extraordinary cases which 
exhibit $>100 \%$ leakage rates $(237 \%$ in power- $1 p-N)$. Figure SF4a suggests that the power-exit retards electro-mobility learning, leading to lock-ins of inefficient $\mathrm{CtL}$ and oil. This (small-magnitude) feedback is robust to coalition size but becomes overshadowed by other responses, resulting in a $56 \%$ carbon leakage rate in power-3p-N.

Comparatively, the demand-exit tempers leakage: $72 \%$ in demand-1p-N and $17 \%$ in demand-3p-N. Irrespective of policy choice, we find that global carbon leakage rates decrease as the coalition grows, and intra-coalition leakage dwarfs extra-coalition leakage with sufficiently large policy uptake (all $2 p$ and $3 p)$. These findings are all robust across Covid recovery scenarios.

\section{Low-Carbon Substitution}

The impact of the power-exit on VRE ranges from -3EJ in $1 p-N$ to $348 \mathrm{EJ}$ in $3 p-N$. The decline in $1 p$ VRE penetration is another consequence of the negative electro-mobility feedback. Bioenergy and other low-carbon energy (Bio\&LCE) deployment experiences marginal upticks of 2-55EJ (1p-3p). Under a demand-exit-neutral regime, these second-order effects range from 112-2070EJ for VRE and 63-1320EJ for Bio\&LCE.

\section{Sectoral Ambition}

We demonstrate that the demand-exit policy is $38 \mathrm{x}$ as effective at phasing out coal and $27 \mathrm{x}$ as potent at $\mathrm{CO}_{2}$ abatement as the power-exit in our most optimistic scenarios - green Covid recovery with virtually global participation (3p). Figure 5 compares the PE trajectories of demand-3p-G and power$3 p-G$ against NPi-green, NDC-green, and $1.5^{\circ} \mathrm{C}$ to visualise their aggregate effects and illuminate the remaining transformations necessary. The most glaring divergence between $N P i-G$ and $1.5^{\circ} \mathrm{C}$ pathways is the 17-fold difference in non-electric coal consumption, which the power-exit further exacerbates.

Figure 5 suggests that natural gas restrictions and bioenergy support are the most urgent priorities after coal, given the sharp, immediate bifurcation between their $1.5^{\circ} \mathrm{C}$ trajectories and all other pathways. Moreover, demand-3p-G incentivises an additional 780EJ gas and 2100EJ oil (Figure SF2), which can be avoided with immediate and sustained investment in renewable industry and transport fuels.

\section{Covid-19 Recovery and Path Dependency}

Our three data-driven scenarios of post-Covid infrastructure (Appendix I) span a range of $1670 \mathrm{GW}$ $2320 \mathrm{GW}$ of coal power capacity in 2025 iii. DPE demonstrates the path-dependence of PPCA expansion to these near-term uncertainties. Most notably, China accedes in neutral-2p (1070GW national 2025 capacity) and green-2p (980GW) scenarios but abstains in brown-2p (1310GW). Figure 3 illustrates the dynamic impacts of China's decision while Figure 4 shows the disparities in long-term prospects.

We report coal efficacy indices (1p-3p range) of .29 (.03-.76) for demand-brown and .53 (.06-.86) for demand-green, and mitigation efficacy scores of .12 (.01-.33) and .23 (.02-.38), respectively. Powerexit scenarios exhibit minimal overall sensitivity all analysis dimensions, meanwhile, with coal efficacy scores ranging between -.03 (brown-1p) and .02 (green-3p), and mitigation efficacies between - .01 and .01. Nevertheless, these results suggests a robust negative correlation between near-term coal power capacity and long-term PPCA efficacy. Greener public investment and regulatory decisions at this critical juncture not only reduce immediate emissions but also have legacy effects that facilitate future feasibility of coal phase-out policies. Myopic brown recovery packages, meanwhile, would impose substantial strain upon future generations to mobilise the necessary transition. 


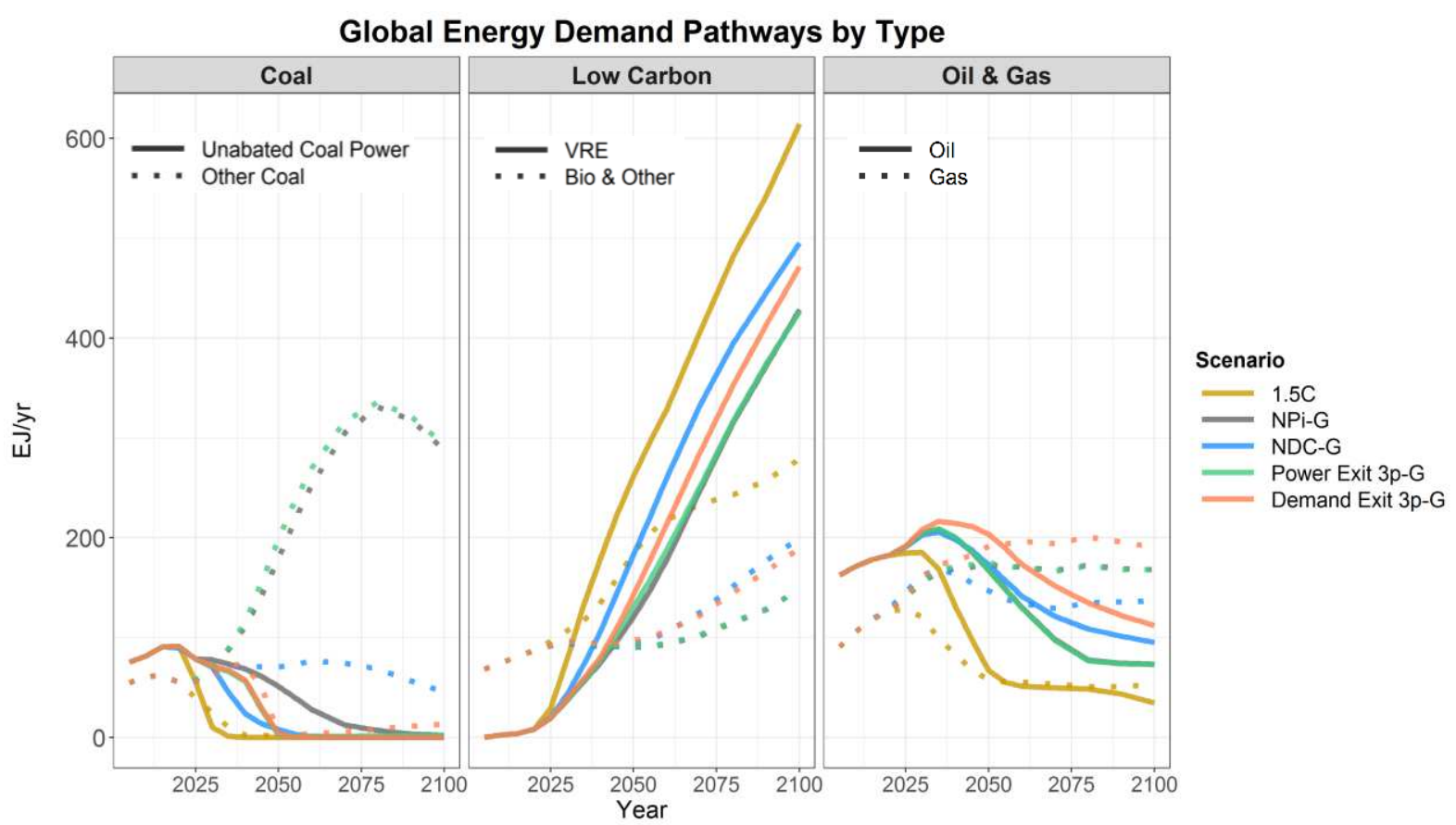

Figure 5. Maximum potential impact of power- and demand-exit policies on global PE demand trajectories from 2005-2100, in comparison with key benchmark scenarios. The green Covid recovery (-G) results in the most $\mathrm{CO}_{2}$ and coal abatement in NPi, NDC, and demand-exit scenarios. Although the power-exit is found, against expectations, to be most effective after a brown recovery, its membership rate is highest in the $3 p-G$ coalition scenario, which captures $99.9 \%$ of 2020 coal consumption in both policy scenarios. The power-3p-G and demand$3 p-G$ scenarios are thus akin to conventional policy evaluation analyses which assess global policy potential.

\section{Discussion}

Interdisciplinary Linkage

The integration of socio-political and techno-economic analyses is an emerging endeavor in climate mitigation research ${ }^{4,7}$. Thus far, attempts to merge empirical social science research on energy transitions with energy-economy models ${ }^{42,43}$ have not robustly improved the realism of mitigation pathways ${ }^{5}$. Our work confronts this challenge by focusing on political dynamics on a global, relative scale, and by narrowing our independent variable pool to IAM-native techno-economic factors, effectively building on a tradition of validating and improving model assumptions through empirical data ${ }^{16,44-46}$. We concede that behavioral, institutional, and cultural factors may hold greater predictive potential, but these fuzzier variables have not yet been prospectively quantified.

The Powerless Power-exit

The PPCA's power-exit declaration cites Rocha et al., an ex-post ensemble analysis of coal-fired electricity in Paris-consistent CEA pathways of select IAMs and energy system models (ESMs) ${ }^{47}$. However, coal power phases out in these scenarios amidst rapid coal and emissions declines economywide. The power-sector bias, evident throughout the coal phase-out discourse ${ }^{24,28,31}$, may be explained in part by data accessibility barriers. The only open-access, comprehensive, coal-asset-level datasetsiv were power-plant-specific ${ }^{48}$ until comparable data on mines $^{v}$ and steel plants ${ }^{\mathrm{vi}}$ were published in 2021. We therefore surmise that the PPCA's sector-exclusivity was motivated by politics - e.g. to encourage maximum participation - and by under-contextualised scientific messaging.

The inadequacy and short-sightedness of the verbatim PPCA is evidenced by the future coal demand profile in REMIND's NPi scenarios; while electricity accounted for $~ 60 \%$ of 2015 coal use ${ }^{49}$, it represents just 16\% cumulatively from 2020-2100 (Figure 5). Moreover, the power-exit generally decreases freerider coal electricity while $\mathrm{CtL}$ and industrial coal use universally increase. Other model baselines robustly corroborate coal demand growth in industry ${ }^{50}$ and transport ${ }^{51}$. A recent review suggested that model scenarios are often overly-dependent on coal, but some power sector bias was evident and it 
found that coal phases-out most readily in REMIND's CEA simulations ${ }^{24}$. The present study does not dispute the urgency of power sector decarbonisation, as electrification is vital to myriad mitigation strategies ${ }^{52}$, but provides grounds for the coalition-of-the-willing to explicitly cover non-electric sectors.

We acknowledge that COALogit cannot accurately estimate demand-exit feasibility since power-exit PPCA pledges form our empirical basis. Our analysis assumes perfect interchangeability to directly compare the two policy options, but a real-world trade-off is anticipated between policy ambition and coalition growth. Stated political ambition, as insinuated by the first-round NDCs, supports this theory. Relative to $1.5^{\circ} \mathrm{C}$-consistent levels, the NDC scenario leaves $10 \mathrm{x}$ as much residual non-electric coal use as unabated coal power, which is phased-out faster than any PPCA scenario modeled here (Figure 5).

Nevertheless, the least effective demand-exit(-1p-B) outperforms the most optimistic power-exit(-3p$G)$, and our median-estimate demand-exit-2p coalitions effect $30 x$ more coal phase-out on average than the virtually-global power-exit-3p scenarios. These outcomes strongly indicate that the PPCA should prioritise sectoral coverage over coalition expansion. Still, expanding the policy to new countries is ultimately essential, and a demand-exit along currently proposed timelines is ultimately insufficient, as even the most optimistic demand-3p-green cannot replicate the coal use pathways of our least-optimistic Paris-compliant benchmark, well-below $2^{\circ} \mathrm{C}$ (Figure 4) vii. $^{\text {vi. }}$

\section{The Policy Feedback Loop}

The evolving coalitions derived by COALogit are largely insensitive to policy choice, i.e. for a given Covid recovery, power-exit and demand-exit coalitions are nearly indistinguishable. This is an artefact of COALogit's parsimonious dependence on coal-power-shares and the fact that the power-exit is simply a subdivision of the demand-exit. Generally, we observe an inverse relationship between OECD coalition size and non-OECD accession probabilities due to extra-coalition leakage of coal electricity, best illustrated by Figure SF1b-d.

Although demand-2p scenarios trigger net-negative extra-coalition coal leakage, free-rider coal power consumption actually increases, discouraging their accession. Power-2p scenarios are also unique, in that extra-coalition coal-fired electricity decreases. However, the root cause is a hindrance of end-use electrification globally, notably exacerbating liquid-fueled transport, the most notoriously challenging end-use to decarbonise across IAM scenarios ${ }^{53}$. Hence, PPCA members must counteract the negative feedbacks provoked by their demand-side efforts and mobilise self-perpetuating policy uptake by ramping up electrification, VRE, and knowledge transfer to maximise technological spillovers.

\section{A Supplementary Supply-exit}

Furthermore, recent literature highlights the importance of complementing demand-side policies with supply-side action ${ }^{54-56}$ through for example mining or export restrictions. This counteracts price depression and leakage, increasing the potential for self-propagation. Given bilateral trade partnerships and spatial variance in coal quality, however, policy efficacy depends upon the specific adopters.

Crucially, the largest anticipated coal consumers in 2045 - China, India, and ASEAN members (Figure 2c) - can each sustain a self-sufficient coal supply. However, their coal infrastructure receives significant overseas financing from OECD-based investors ${ }^{57}$, where divestment campaigns are historically commonplace ${ }^{56}$. Granted, Chinese banks are the world's largest overall coal financiers ${ }^{57}$ and may insulate the domestic industry from foreign politics, but OECD legislatures can conceivably induce coal declines through cross-border financial mechanisms, e.g. debt-for-nature swaps ${ }^{58}$. China's historical 22-year mean plant lifetime (Table 2) and its 2060 carbon neutrality pledge ${ }^{40}$ breed cautious optimism. 


\section{Averting the Next Crisis}

These coal-rich nations also exhibit the highest path-dependence of accession probability to near-term investment decisions. Most glaringly, China falls below the $2 p$ threshold ${ }^{\text {viii }}$ and Indonesia below $3 p$ probability in brown recovery scenarios. Additionally, we observe that numerous highly-probable coalition members within the OECD continue to commission coal power plants in brown and neutral Covid recoveries ${ }^{i x}$. PPCA accession then forces a sudden mass exodus of unamortised capital -a $100 \%$ rate of early retirement ${ }^{x}$ from 2025-2030. Thus, to protect the health of their economy ${ }^{28}$, power grid $^{59}$, citizenry ${ }^{23}$, and global-leader status, OECD governments must cancel their entire coal pipelines ${ }^{60}$.

\section{Future Research}

DPE presents a way forward for inter-disciplinary climate policy research seeking to understand the intersection of techno-economic, socio-political, and climate target feasibility. To enable similarly evidence-based simulations of policy uptake in future studies, empirical research must identify robust correlations between revealed ambition, viz. domestic legislation, and energy-economic variables computed endogenously by forward-looking models. As the remaining window to respect the $1.5^{\circ} \mathrm{C}$ target dwindles ${ }^{2}$, we invite the data science community to contribute their expertise in large-scale regression exercises ${ }^{16,61}$. As more DFS models are derived, they can be merged with IAMs as nested or sequential feedback loops to portray a cohesive, inter-reactive landscape of baseline climate ambition.

Furthermore, parallel research needs to examine supplementary policy options for frontrunners ('early entry points' ${ }^{\prime 62}$ ) that best augment global mitigation efficacy. We offer our median-estimate scenarios as 'living' baselines upon which subsequent DPE and PEA studies can be performed. By capturing the global policy interactions that other real-world developments and policy candidates can have with the PPCA and each other, researchers can identify high-synergy, low-risk policy suites for willing-and-able nations to facilitate energy transitions in less capable economies. Supply-side fossil fuel regulations and carbon pricing are prime candidates given their uptake frequency ${ }^{56}$ and anticipated efficacy ${ }^{55}$. Finally, future work should strive to fully endogenise policy formation and feedback, with maximal temporal resolution, into IAM optimization routines.

\section{References}

1. UNFCCC. Paris Agreement. (2015).

2. Kriegler Elmar et al. Pathways limiting warming to $1.5^{\circ} \mathrm{C}$ : a tale of turning around in no time? Philosophical Transactions of the Royal Society A: Mathematical, Physical and Engineering Sciences 376, 20160457 (2018).

3. Rogelj, J. et al. Chapter 2: Mitigation pathways compatible with $1.5^{\circ} \mathrm{C}$ in the context of sustainable development. in Global Warming of $1.5^{\circ} \mathrm{C}$ an IPCC special report on the impacts of global warming of $1.5^{\circ} \mathrm{C}$ above pre-industrial levels and related global greenhouse gas emission pathways, in the context of strengthening the global response to the threat of climate change (Intergovernmental Panel on Climate Change, 2018).

4. Geels, F. W., Berkhout, F. \& van Vuuren, D. P. Bridging analytical approaches for low-carbon transitions. Nature Clim. Change 6, 576-583 (2016).

5. Hirt, L. F., Schell, G., Sahakian, M. \& Trutnevyte, E. A review of linking models and socio-technical transitions theories for energy and climate solutions. Environmental Innovation and Societal Transitions 35, 162-179 (2020).

6. Jewell, J. \& Cherp, A. On the political feasibility of climate change mitigation pathways: Is it too late to keep warming below $1.5^{\circ} \mathrm{C}$ ? WIREs Climate Change 11, e621 (2020).

7. Trutnevyte, E. et al. Societal Transformations in Models for Energy and Climate Policy: The Ambitious Next Step. One Earth 1, 423-433 (2019). 
8. Riahi, K. et al. Locked into Copenhagen pledges - Implications of short-term emission targets for the cost and feasibility of long-term climate goals. Technological Forecasting and Social Change 90, 8-23 (2015).

9. Bauer, N. et al. Quantification of an efficiency-sovereignty trade-off in climate policy. Nature 588, 261-266 (2020).

10. Schreyer, F. et al. Common but differentiated leadership: strategies and challenges for carbon neutrality by 2050 across industrialized economies. Environmental Research Letters 15, 114016 (2020).

11. Nordhaus, W. Climate Clubs: Overcoming Free-riding in International Climate Policy. American Economic Review 105, 1339-1370 (2015).

12. Voigt, C. The Compliance and Implementation Mechanism of the Paris Agreement. RECIEL 25, 161-173 (2016).

13. Baumstark, L. et al. REMIND2.1: Transformation and innovation dynamics of the energyeconomic system within climate and sustainability limits. Geoscientific Model Development Discussions 1-50 (2021) doi:10.5194/gmd-2021-85.

14. Sabel, C. F. \& Victor, D. G. Governing global problems under uncertainty: making bottom-up climate policy work. Climatic Change 144, 15-27 (2017).

15. Meckling, J., Kelsey, N., Biber, E. \& Zysman, J. Winning coalitions for climate policy. Science 349, 1170-1171 (2015).

16. Cherp, A., Vinichenko, V., Tosun, J., Gordon, J. A. \& Jewell, J. National growth dynamics of wind and solar power compared to the growth required for global climate targets. Nat Energy 6, 742754 (2021).

17. Lamb, W. F. \& Minx, J. C. The political economy of national climate policy: Architectures of constraint and a typology of countries. Energy Research \& Social Science 64, 101429 (2020).

18. Jewell, J., Vinichenko, V., Nacke, L. \& Cherp, A. Prospects for powering past coal. Nat. Clim. Chang. 9, 592-597 (2019).

19. Jakob, M., Flachsland, C., Steckel, J. C. \& Urpelainen, J. The political economy of climate and energy policy: A Theoretical Framework. 22 (Working Paper).

20. Pahle, M. et al. Sequencing to ratchet up climate policy stringency. Nature Climate Change 8 , 861-867 (2018).

21. Bauer, N. et al. $\mathrm{CO} 2$ emission mitigation and fossil fuel markets: Dynamic and international aspects of climate policies. Technological Forecasting and Social Change 90, Part A, 243-256 (2015).

22. McGlade, C. \& Ekins, P. The geographical distribution of fossil fuels unused when limiting global warming to $2^{\circ} \mathrm{C}$. Nature 517, 187-190 (2015).

23. Rauner, S., Bauer, N., Dirnacher, A. \& Van Dingenen, R. Coal exit health and environmental damage reductions outweigh economic impacts. Nature Climate Change (accepted) (2020).

24. Minx, J. et al. Coal transitions - Part 2: Phase-out dynamics in global long-term mitigation scenarios. Environmental Research Letters (submitted) (Submitted).

25. Bauer, N. et al. Assessing global fossil fuel availability in a scenario framework. Energy 111, 580592 (2016).

26. Tong, D. et al. Committed emissions from existing energy infrastructure jeopardize $1.5^{\circ} \mathrm{C}$ climate target. Nature 1 (2019) doi:10.1038/s41586-019-1364-3.

27. Fofrich, R. et al. Early retirement of power plants in climate mitigation scenarios. Environ. Res. Lett. 15, 094064 (2020). 
28. Johnson, N. et al. Stranded on a low-carbon planet: Implications of climate policy for the phaseout of coal-based power plants. Technological Forecasting and Social Change 90, 89-102 (2015).

29. Diluiso, F. et al. Coal transitions - part 1: a systematic map and review of case study learnings from regional, national, and local coal phase-out experiences. Environ. Res. Lett. 16, 113003 (2021).

30. Muttitt, G., Price, J., Pye, S. \& Welsby, D. Ignoring socio-political realities in energy models overweights coal power phaseout compared to other climate mitigation options. (Unpublished Manuscript).

31. Edenhofer, O. King Coal and the queen of subsidies. Science 349, 1286-1287 (2015).

32. Edenhofer, O., Steckel, J. C., Jakob, M. \& Bertram, C. Reports of coal's terminal decline may be exaggerated. Environ. Res. Lett. 13, 024019 (2018).

33. Jakob, M. et al. The future of coal in a carbon-constrained climate. Nat. Clim. Chang. 10, 704-707 (2020).

34. Blondeel, M., Van de Graaf, T. \& Haesebrouck, T. Moving beyond coal: Exploring and explaining the Powering Past Coal Alliance. Energy Research \& Social Science 59, 101304 (2020).

35. Bertram, C. et al. COVID-19-induced low power demand and market forces starkly reduce $\mathrm{CO} 2$ emissions. Nat. Clim. Chang. (2021) doi:10.1038/s41558-021-00987-x.

36. Gilabert, P. \& Lawford-Smith, H. Political Feasibility: A Conceptual Exploration. Political Studies 60, 809-825 (2012).

37. Winkelmann, R. et al. Social tipping processes towards climate action: A conceptual framework. Ecological Economics 192, 107242 (2022).

38. Otto, I. M. et al. Social tipping dynamics for stabilizing Earth's climate by 2050. Proc Natl Acad Sci USA 201900577 (2020) doi:10.1073/pnas.1900577117.

39. Bond, K., Fulton, M. \& Hobley, A. The political tipping point: Why the politics of energy will follow the economics. (2019).

40. Bauer, N. et al. The $1.5^{\circ} \mathrm{C}$ global climate target and China's carbon neutrality pledge. Science (in review).

41. Fricko, O. SSP2: A middle of the road scenario for the 21st century. Global Environmental Change This Special Issue. (2016).

42. Li, F. G. N., Trutnevyte, E. \& Strachan, N. A review of socio-technical energy transition (STET) models. Technological Forecasting and Social Change 100, 290-305 (2015).

43. Cherp, A., Vinichenko, V., Jewell, J., Brutschin, E. \& Sovacool, B. Integrating techno-economic, socio-technical and political perspectives on national energy transitions: A meta-theoretical framework. Energy Research \& Social Science 37, 175-190 (2018).

44. van Sluisveld, M. A. E. et al. Comparing future patterns of energy system change in $2^{\circ} \mathrm{C}$ scenarios with historically observed rates of change. Global Environmental Change 35, 436-449 (2015).

45. Wilson, C., Grubler, A., Bauer, N., Krey, V. \& Riahi, K. Future capacity growth of energy technologies: are scenarios consistent with historical evidence? Climatic Change 118, 381-395 (2013).

46. Loftus, P. J., Cohen, A. M., Long, J. C. S. \& Jenkins, J. D. A critical review of global decarbonization scenarios: what do they tell us about feasibility? WIREs Clim Change 6, 93-112 (2015).

47. Rocha, M. et al. IMPLICATIONS OF THE PARIS AGREEMENT FOR COAL USE IN THE POWER SECTOR. https://climateanalytics.org/media/climateanalytics-coalreport_nov2016_1.pdf (2016).

48. Global Energy Monitor. Global Coal Plant Tracker January 2021. EndCoal.org https://endcoal.org/global-coal-plant-tracker/ (2021). 
49. IEA. World energy balances. IEA World Energy Statistics and Balances https://doi.org/10.1787/data-00512-en (2017).

50. Edelenbosch, O. Y. et al. Comparing projections of industrial energy demand and greenhouse gas emissions in long-term energy models. Energy 122, 701-710 (2017).

51. Ritchie, J. \& Dowlatabadi, H. Why do climate change scenarios return to coal? Energy 140, 12761291 (2017).

52. Gunnar Luderer et al. Accelerated electrification based on cheap renewables facilitates reaching Paris Climate targets. Submitted to Nature Energy.

53. Luderer, G. et al. Residual fossil $\mathrm{CO} 2$ emissions in $1.5-2{ }^{\circ} \mathrm{C}$ pathways. Nature Climate Change 8 , 626-633 (2018).

54. Asheim, G. B. et al. The case for a supply-side climate treaty. Science 365, 325-327 (2019).

55. Erickson, P., Lazarus, M. \& Piggot, G. Limiting fossil fuel production as the next big step in climate policy. Nature Climate Change 1 (2018) doi:10.1038/s41558-018-0337-0.

56. Gaulin, N. \& Le Billon, P. Climate change and fossil fuel production cuts: assessing global supplyside constraints and policy implications. Climate Policy 1-14 (2020) doi:10.1080/14693062.2020.1725409.

57. Manych, N., Steckel, J. C. \& Jakob, M. Finance-based accounting of coal emissions. Environ. Res. Lett. 16, 044028 (2021).

58. Cassimon, D., Prowse, M. \& Essers, D. The pitfalls and potential of debt-for-nature swaps: A USIndonesian case study. Global Environmental Change 21, 93-102 (2011).

59. Simshauser, P. \& Gilmore, J. Climate policy discontinuity \& Australia's 2016-2021 renewable investment supercycle (Accepted Manuscript). Energy Policy-forthcoming (2022).

60. International Energy Agency. Net Zero by 2050: A Roadmap for the Global Energy Sector. 224 https://www.iea.org/reports/net-zero-by-2050 (2021).

61. Levi, S. Why hate carbon taxes? Machine learning evidence on the roles of personal responsibility, trust, revenue recycling, and other factors across 23 European countries. Energy Research \& Social Science 73, 101883 (2021).

62. Bertram, C. et al. Complementing carbon prices with technology policies to keep climate targets within reach. Nature Climate Change 5, 235-239 (2015).

\footnotetext{
' The participating subnational governments and private sector organisations are not considered in our study.

ii Countries are defined according to the ISO 3166-1 convention (249 total).

iii For reference, we estimate $2160 \mathrm{GW}$ when extrapolating with globally-uniform 40 -year lifespans and $100 \%$ project completion as assumed in prior literature (see Figure A1) ${ }^{26}$.

iv Global Energy Monitor. Global Coal Public Finance Tracker July 2020. EndCoal.org.

$\checkmark$ Global Energy Monitor. Global Coal Mine Tracker January 2021. EndCoal.org.

vi Global Energy Monitor. Global Steel Plant Tracker January 2021. EndCoal.org.

vii This may well be an artefact of REMIND-COALogit's low temporal resolution, as more 'reasonable' pathways could be modeled by allowing coalition accession and policy enactment along a rolling horizon, i.e. in each REMIND period, which would be highly resource-intensive. Future DPE implementations may explore reducing the IAM optimisation horizon in each iteration to enable this.

viii China did not breach the $2 p$ coalition in any scenario until after COALogit was re-calibrated to account for the accession of Spain, Croatia, Albania, North Macedonia, and Montenegro in July 2021, illustrating the dynamism of the DFS, i.e. the sensitivity of COALogit to relatively minor developments.

ix Japan and South Korea in the green recovery as well.
} 
${ }^{x}$ Under default REMIND assumptions, early retirement is limited to $9 \%$ p.a. (45\% per 5-year time-step). Several regions were thus mathematically infeasible without removing this constraint. 


\section{Figures}

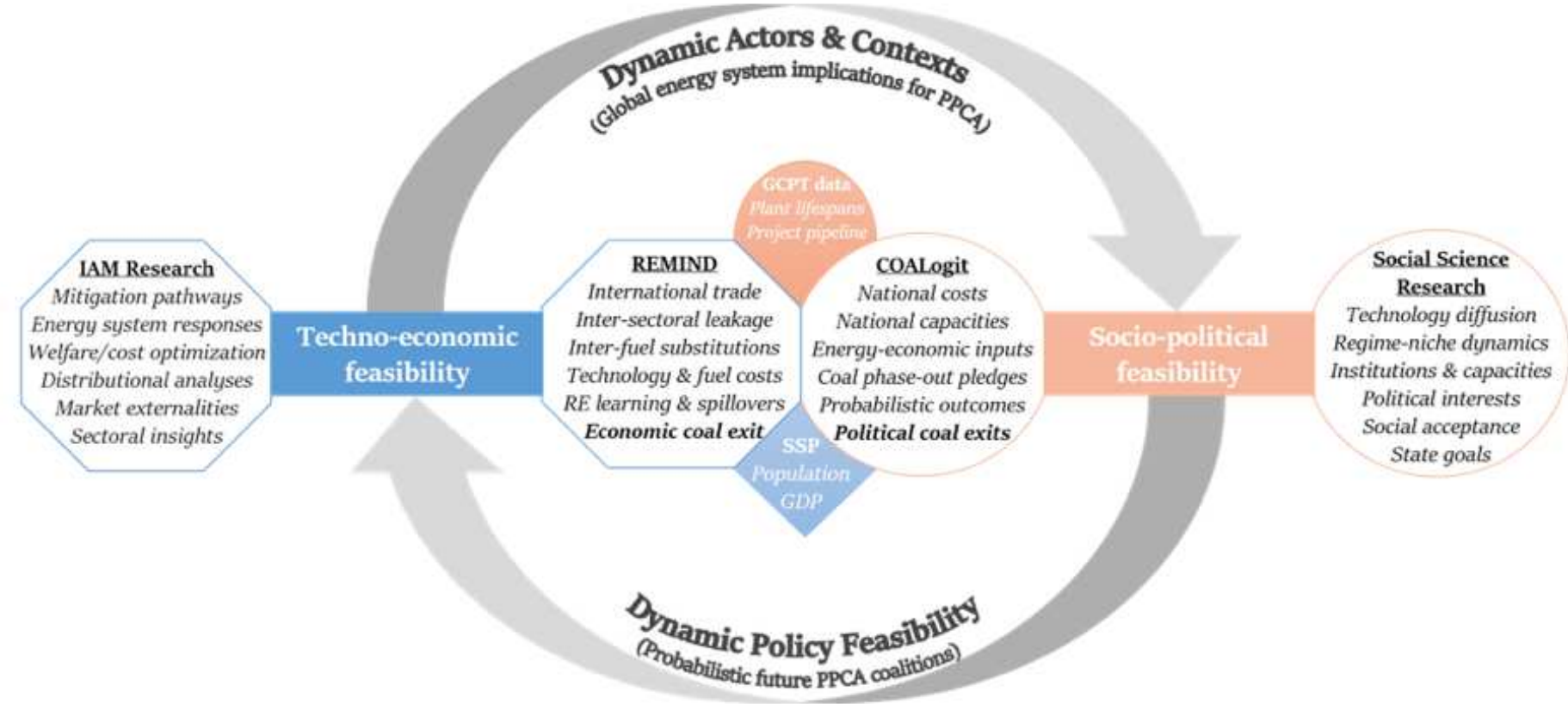

\section{Figure 1}

Dynamic Policy Evaluation depicted as a cyclical, iterative interface between techno-economic and sociopolitical analyses, both in the present study (inner circle and parentheses) and in the broader context of integrating IAMs and social sciences (outer circle). Policy feedbacks in this study begin with the impacts of currently legislated coal exits on national energy sectors, regional energy systems, and the global energy market, i.e. dynamic actors and contexts, via REMIND-endogenous effects (inner blue hexagon). REMIND feeds future per-capita GDP and coal-power-shares to COALogit, which infers national probabilities of PPCA accession. These political prospects are translated to coalition scenarios and policy stringency coefficients (Methods) which inform regionally-differentiated policy uptake in REMIND. Staged accession is simulated by repeating the cycle in different model time-steps. 


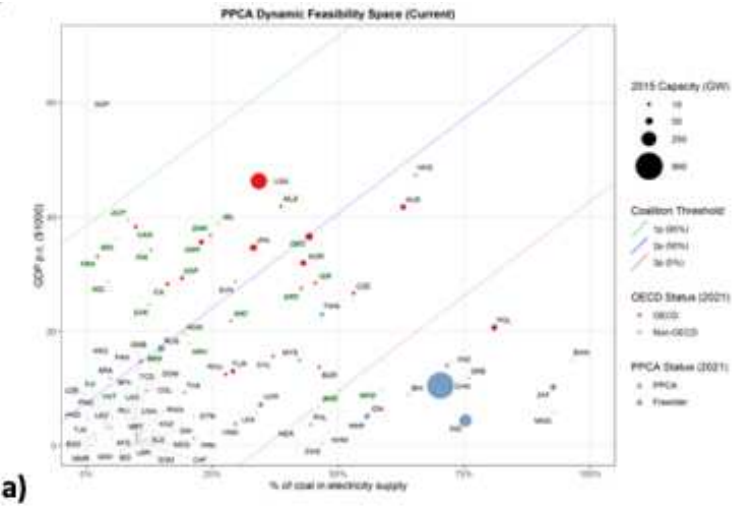

b)

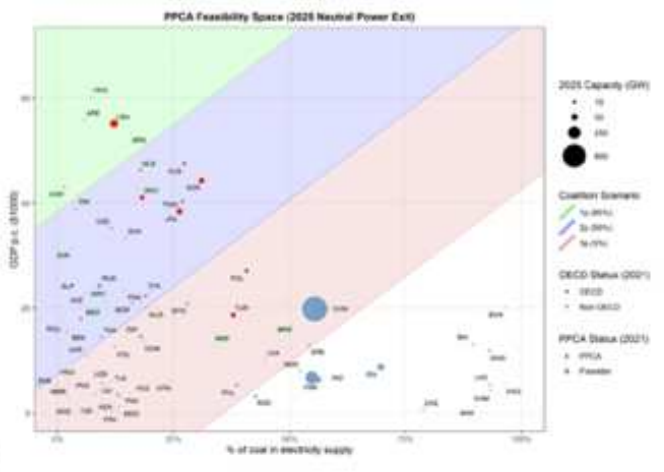

c)

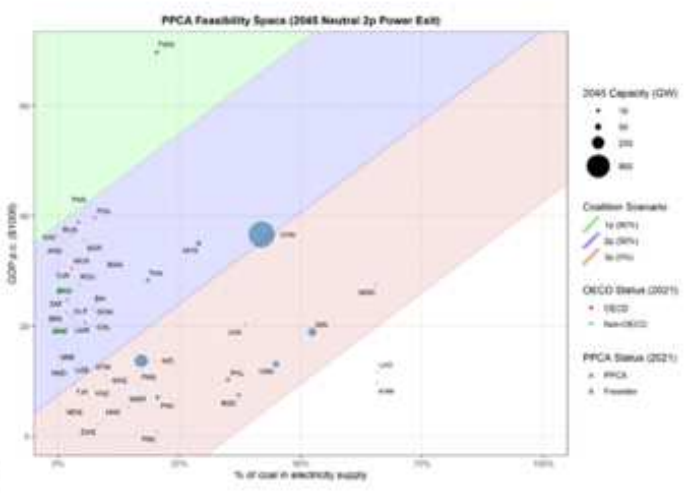

d)

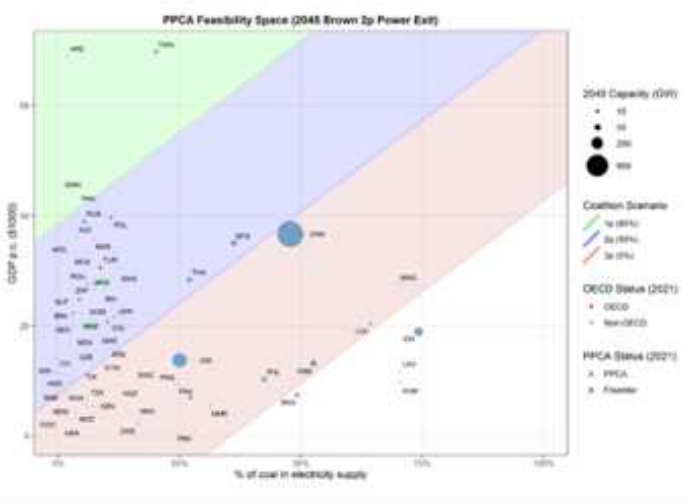

Figure 2

Dynamic feasibility of PPCA adoption in each country according to COALogit. Logistic regression of Alliance membership based on GDP per capita (indicator of state capacity) and coal-power-share (proxy for coal phase-out policy cost) in 2015 (a), 2025 (b) and 2045 (c \& d), depicting all nations with >1\% coalpower-share in the respective year. Bubble size indicates the operating coal capacity at that time, while 'PPCA Status' and 'OECD Status' reflect membership as of July 2021. The shaded areas show the 
probabilistic coalition scenarios: proven (1p), proven + probable (2p), and proven + probable + possible (3p). Panels (b) and (c) represent the neutral Covid recovery - (c) follows directly from a 2030 power-exit by OECD-2p coalition members in (b) - while (d) illustrates the brown recovery, following from Figure SF1a.

a)

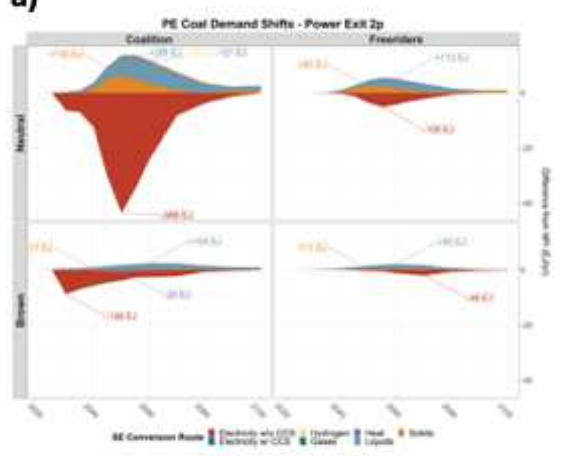

b)

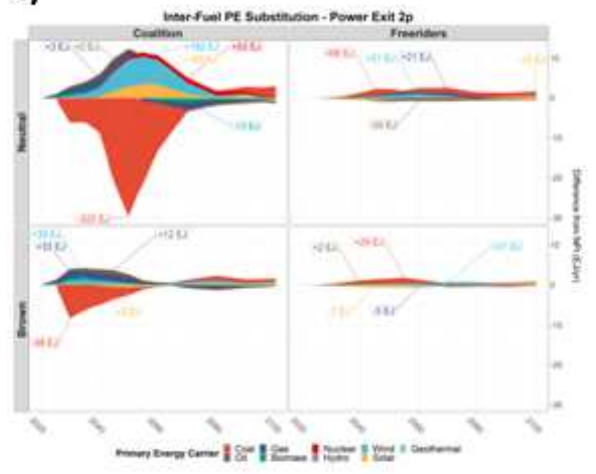

c)|

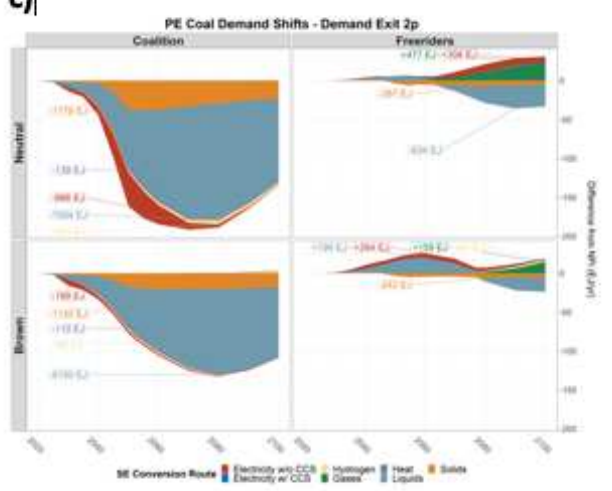

d)

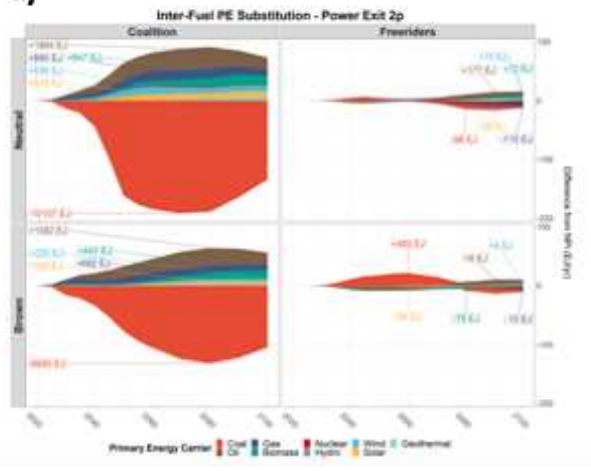

Figure 3 
Annual differences in coal $(a+c)$ or primary energy $(b+d)$ demand from NPi in probable power-exit $(a-b)$ and demand-exit (c-d) scenarios, with the cumulative differences denoted by labels. Columns distinguish between coalition members and free-riders in the Covid recovery scenario represented by each row. Coal demand is given in primary energy (PE) values and categorised by secondary energy (SE) conversion route. Generally, negative areas in the 'Coalition' column reflect the intended policy effect, while all other differences indicate system feedbacks.

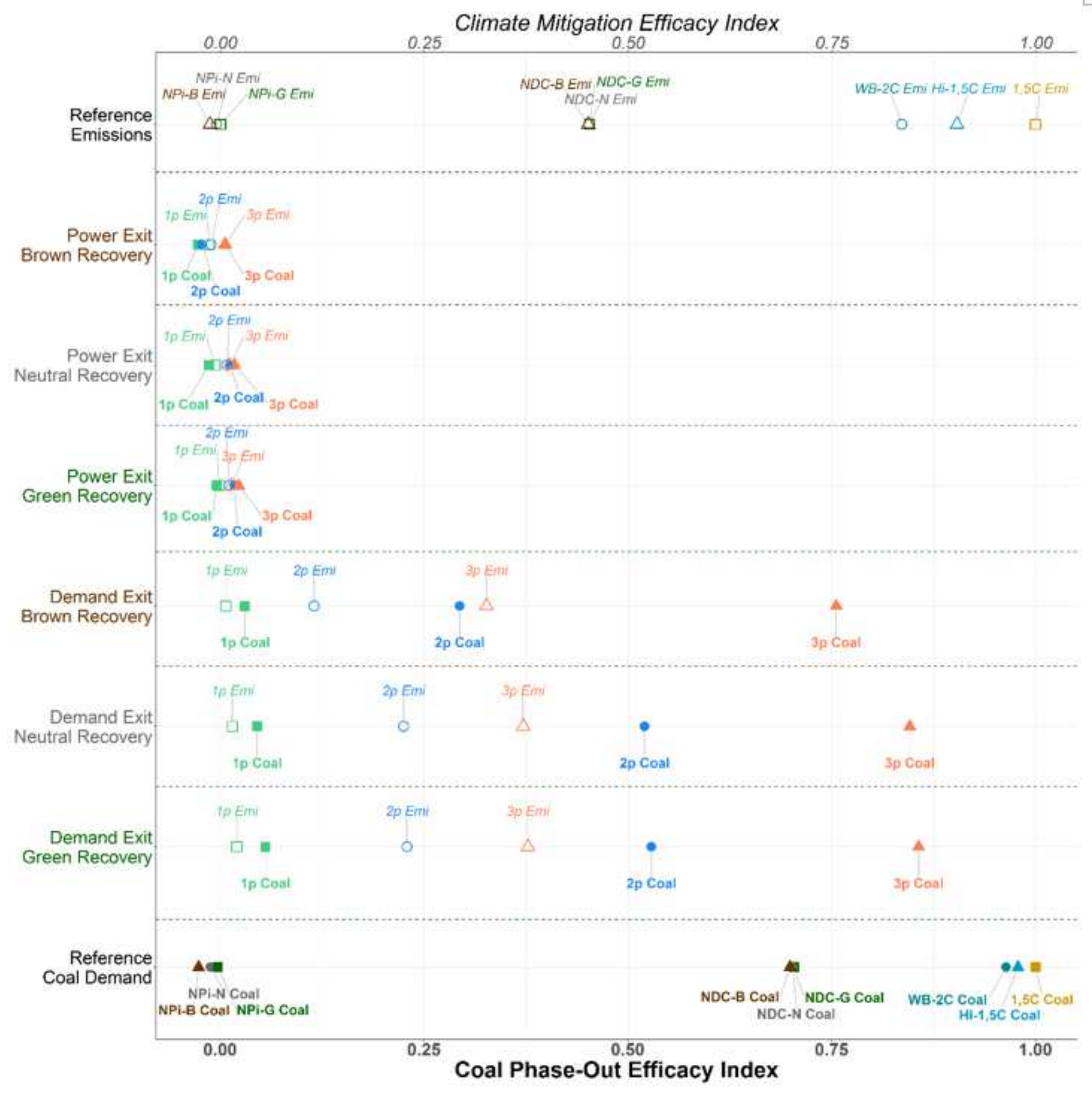

\section{Figure 4}


Compilation of all 18 scenarios, assessed for their efficacy relative to $1.50 \mathrm{C}$ pathways in terms of coal phase-out (indicated by the lower $\mathrm{x}$-axis, solid points, and bold font) and $\mathrm{CO} 2$ emissions reductions (upper $x$-axis, hollow points, italic font). Each scenario is scored on an index between 0 and 1 , where 0 represents the NPi reference scenario (without Covid considerations) and 1 corresponds to $1.50 \mathrm{C}$. For each row, the $2 p$ points can be considered the DPE median estimate, and the range between $1 p$ and $3 p$ indicates the uncertainty range.

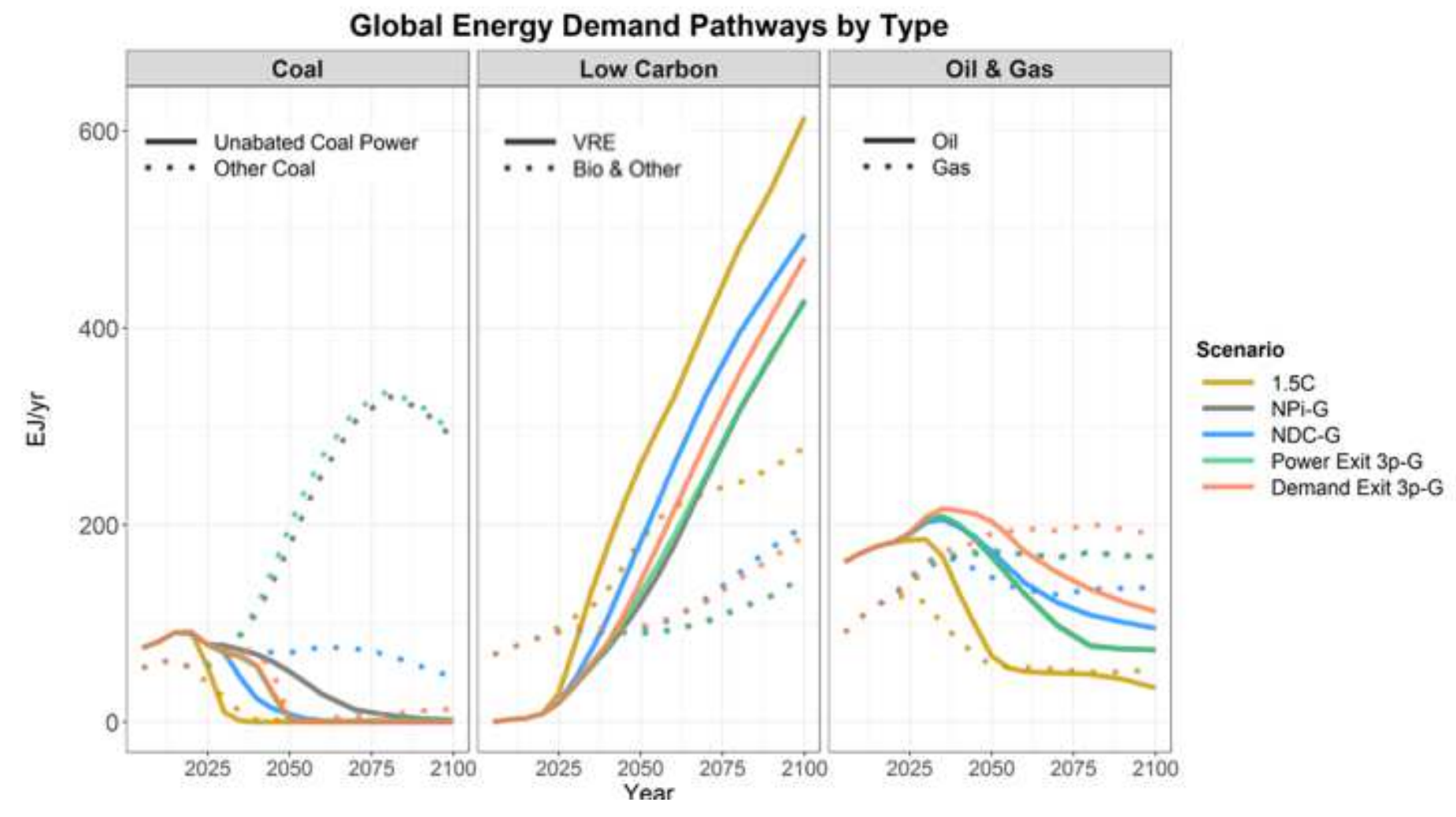

Figure 5

Maximum potential impact of power- and demand-exit policies on global PE demand trajectories from 2005-2100, in comparison with key benchmark scenarios. The green Covid recovery (-G) results in the most $\mathrm{CO} 2$ and coal abatement in NPi, NDC, and demand-exit scenarios. Although the power-exit is found, against expectations, to be most effective after a brown recovery, its membership rate is highest in the $3 p$ $\mathrm{G}$ coalition scenario, which captures $99.9 \%$ of 2020 coal consumption in both policy scenarios. The power-3p-G and demand 3p-G scenarios are thus akin to conventional policy evaluation analyses which assess global policy potential

\section{Supplementary Files}

This is a list of supplementary files associated with this preprint. Click to download.

- Methodsfinal.docx

- NEnergyappendixDPEPPCA.docx

- NEnergysupplementDPEPPCA.docx 
- DPEintermediatecascadescenarios.csv 